\title{
ENSO Influence on TRMM Tropical Oceanic Precipitation Characteristics and Rain Rates
}

\author{
David S. Henderson, Christian D. Kummerow, and Wesley Berg \\ Department of Atmospheric Science, Colorado State University, Fort Collins, Colorado
}

(Manuscript received 25 April 2017, in final form 6 February 2018)

\begin{abstract}
Discrepancies between Tropical Rainfall Measuring Mission (TRMM) Microwave Imager (TMI) and Precipitation Radar (PR) oceanic rainfall retrievals are prevalent between El Niño and La Niña conditions with TMI exhibiting systematic shifts in precipitation. To investigate the causality of this relationship, this paper focuses on the evolution of precipitation organization between El Niño and La Niña and their impacts on TRMM precipitation. The results indicate that discrepancies are related to shifts from isolated deep convection during La Niña toward organized precipitation during El Niño with the largest variability occurring in the Pacific basins. During El Niño, organized systems are more frequent, have increased areal coverage of stratiform rainfall, and penetrate deeper into the troposphere compared to La Niña. The increased stratiform raining fraction leads to larger increases in TMI rain rates than PR rain rate retrievals. Reanalysis and water vapor data from the Atmospheric Infrared Sounder (AIRS) indicate that organized systems are aided by midtropospheric moisture increases accompanied by increased convective frequency. During La Niña, tropical rainfall is dominated by isolated deep convection due to drier midtropospheric conditions and strong mid- and upper-level zonal wind shear. To examine tropical rainfall-sea surface temperature relations, regime-based bias corrections derived using ground validation $(\mathrm{GV})$ measurements are applied to the TRMM rain estimates. The robust connection with GV-derived biases and oceanic precipitation leads to a reduction in TMI-PR regional differences and tropics-wide precipitation anomalies. The improved agreement between PR and TMI estimates yields positive responses of precipitation to tropical SSTs of $10 \%{ }^{\circ} \mathrm{C}^{-1}$ and $17 \%{ }^{\circ} \mathrm{C}^{-1}$, respectively, consistent with $15 \%{ }^{\circ} \mathrm{C}^{-1}$ from the Global Precipitation Climatology Project (GPCP).
\end{abstract}

\section{Introduction}

The launch of the Tropical Rainfall Measuring Mission (TRMM; Kummerow et al. 1998) in 1997, and the followon Global Precipitation Mission in 2014 (Hou et al. 2014) has provided in-depth detail of the physical structures and properties of precipitating systems across the globe. The continued use of satellite-observed precipitation remains important as ground-based observations are sparsely distributed, particularly over the oceans. This importance is amplified by the fact that we currently cannot accurately represent rainfall in global models (Stephens et al. 2010). However, while satellite retrievals are continually improving, discrepancies in tropical rain rates still exist between both model and various satellite rain rate estimates. One such discrepancy occurs during El Niño events where tropical ocean waters exhibit equatorial warm anomalies in sea surface temperatures (SSTs)

Corresponding author: David Henderson, henderson@atmos. colostate.edu originating from the west coast of South America extend out toward the central and west Pacific Ocean basins leading to tropics-wide changes in precipitation intensity (Soden 2000; Held and Soden 2006).

Wang et al. (2008) compared ENSO variability $\left(25^{\circ} \mathrm{S}-\right.$ $25^{\circ} \mathrm{N}$ ) in monthly precipitation data from the TRMM Microwave Imager (TMI) and Precipitation Radar (PR) to rain estimates from the radiometer-based Global Precipitation Climatology Project (GPCP). Over the tropical oceans, passive microwave driven precipitation datasets from GPCP and TMI show increases in tropical oceanic rainfall of $15.4 \%$ and $16.7 \%{ }^{\circ} \mathrm{C}^{-1}$, respectively, related to ENSO variability. This SST relationship is less prevalent in PR rainfall estimates where little correlation exists between SST and oceanic precipitation with sensitivity of $1.7 \%-4.4 \%{ }^{\circ} \mathrm{C}^{-1}$ (Gu et al. 2007; Wang et al. 2008). Similar estimates are found in Liu et al. (2013), who discovered a robust relationship between increasing SST and CMIP5 models in the tropics $\left(30^{\circ} \mathrm{S}-\right.$ $30^{\circ} \mathrm{N}$ ), but at a magnitude $3-5$ times less than the GPCP 
and TMI estimates with an average increase of $3.1 \%{ }^{\circ} \mathrm{C}^{-1}$.

Accurate knowledge of precipitation characteristics is also necessary for retrievals of latent heating, which provide insight into the magnitude and orientation of vertical heating profiles (e.g., Tao et al. 2001; Shige et al. 2004). Incorrect representation of precipitation and its characteristics can have significant effects when deriving the impact of precipitation on the global circulation (Schumacher et al. 2004). Recent work has demonstrated that accurate heating profiles might depend not only on precipitation characteristics, but also on the weather state where the precipitation is developing (e.g., Back and Bretherton 2006; Elsaesser et al. 2010; Handlos and Back 2014; Yokoyama et al. 2014). In CMIP5 models, the inadequate representation of rainfall processes leads to large uncertainty when deriving the ENSO amplitude, spatial patterns, atmospheric teleconnections, and the magnitude of precipitation change for different climate states (e.g., Su and Jiang 2013; Watanabe et al. 2012; Houze et al. 2015), where little improvement was found from CMIP3 to CMIP5. Further, Liu et al. (2013) observed that a large spread in month-to-month rainfall estimates exists between the CMIP5 ensemble members. With the prospect of future climate scenarios pointing to a more El Niño-like state (e.g., Vecchi and Soden 2007; Vecchi and Wittenberg 2010), it is imperative to further constrain how precipitation changes globally with a changing climate.

To better understand the variability of global and regional rainfall, or infer global rainfall variability given an altered climate, a consensus must exist in rainfall observations. This process begins by understanding the main factors that drive the interannual variability observed in the TRMM rain rate retrievals. The different sensitivities in the observed precipitation estimates could be attributed to how the retrievals interpret more frequent convection with higher rainfall intensity occurring with El Niño events (Lau and Wu 2011). Previous research has implemented various classification methodologies to record the climatologies and variations of assorted precipitating systems across the tropics (e.g., Houze et al. 2007; Liu et al. 2008; Elsaesser et al. 2010; Zipser et al. 2006); however, it is still difficult to accurately describe how regional variability in the makeup of the convective population directly influences tropicswide averaged TRMM TMI and PR rainfall estimates.

Liu and Zipser (2014) derived mean TMI-PR differences for version 7 TRMM products and found the largest discrepancies occurring in the central and east Pacific, where TMI rainfall generally overestimates PR, and the largest TMI underestimates of PR rain rates residing in the Indian Ocean; differences in both regions exceed 30\%. The PR has been observed to underestimate rain rates due to errors in deriving drop size distributions and rainfall inhomogeneity in the PR field of view (e.g., Iguchi et al. 2009; Munchak et al. 2012; Kirstetter et al. 2014). TMI rain rates have been observed to overestimate regions of stratiform rainfall and underestimate in convective rainfall due to difficulty in differentiating convective and stratiform rainfall in a Bayesian retrieval framework (e.g., Henderson et al. 2017a; Carr et al. 2015). As described in Carr et al. (2015), these TMI biases due to rain-type partitioning are likely correlated to the fraction of convection occurring in the TMI field of view. Henderson et al. (2017a) used TRMM ground validation (GV) data from the Kwajalein Atoll to establish distinct bias patterns in TMI and PR rain rate estimates as a function of defined precipitation regimes and their convective fraction using methodologies from Elsaesser et al. (2010). They found that variability in these precipitation regimes, in particular rainfall from organized precipitation [mesoscale convective systems (MCSs)], was driving differences between TMI and PR rain estimates during El Niño events over the Kwajalein region, whereas TMI-PR rain rate differences during La Niña events were driven by more isolated deep convection.

This work looks to expand upon the results of Henderson et al. (2017a) to examine the relationship between regional variations in precipitating systems and environmental characteristics related to TMI-PR discrepancies across the tropical oceans $\left(25^{\circ} \mathrm{S}-25^{\circ} \mathrm{N}\right)$. ENSO-related differences between the TRMM TMI and PR rain rate retrievals have been linked to environmental characteristics and to systematic changes in regional cloud properties over time (e.g., Berg et al. 2002, 2006; Masunaga et al. 2005; Henderson et al. 2017a). Therefore, focusing on the regional differences between the products over time can act as a diagnostic tool to discover where changes in precipitation properties are occurring between ENSO phases. Combining this knowledge with the regime-based study of Henderson et al. (2017a), we observe the variations in regional precipitation organization, as identified by TRMM PR characteristics, to identify the physical sources leading to the interannual variability observed in TMI and PR rainfall estimates.

The analysis is completed by focusing on multiple ENSO events occurring throughout the TRMM mission to observe regional changes in precipitation organization. These changes are then related to regional TMIPR rain rate differences to examine their impact on tropical monthly mean rain rate anomalies occurring over time. Further, because tropical rainfall variability is largely driven by large-scale circulation changes in the 
Walker circulation, and MCS formation is affected by changes in large-scale environmental conditions (e.g., Houze 2004), we relate the regional changes in precipitation regimes with their respective changes in convective available potential energy (CAPE), SST, humidity, and wind shear. The examination of spatial and environmental cases is initially focused regionally at the Kwajalein ground validation site, which provides high temporal resolution sampling to evaluate the physical changes occurring in precipitation characteristics. The results are then broadened to observe TRMM precipitation variability over the tropical oceans. The final section will focus on applying GV-derived biases in the defined precipitation regimes to investigate how we might further constrain observationally based estimates of ENSO-induced rain rate variability occurring over the tropical oceans.

\section{Data and methodology}

This work focuses on the version 7 TRMM TMI 2A12 and TRMM PR $2 \mathrm{~A} 25$ products from $25^{\circ} \mathrm{S}-25^{\circ} \mathrm{N}$ over the tropical oceans for ENSO events occurring from 1998 to 2013, where El Niño and La Niña events are categorized using a $\pm 0.5^{\circ} \mathrm{C}$ threshold in the ENSO-3.4 index (http:// www.cpc.ncep.noaa.gov/data/indices/sstoi.indices). The TMI radiometer passively observes radiation using nine channels with horizontal and vertical polarization at $10.65,19.35,37.0$, and $85.5 \mathrm{GHz}$ and vertical-only polarization at $21.3 \mathrm{GHz}$. Emissivity of the ocean surface is lower than that of land; therefore, liquid hydrometeors (i.e., clouds and rain) are clearly detectable over oceans for the TMI radiance channels. The TRMM TMI 2A12 version 7 rain rate product is derived using the Goddard Profiling Algorithm (GPROF) (Kummerow et al. 2015), which utilizes a Bayesian framework to retrieve hydrometer profiles. Data from the TRMM PR version 7 $2 \mathrm{~A} 25$ product provide radar-based surface rain rate estimates and rain type partitioning from a $13.8-\mathrm{GHz}(\mathrm{Ku}$ band) radar. For this work, we use the near-surface rain rate estimate from the PR TRMM 2 A25 product and stratiform/convective partitioning defined using vertical and horizontal reflectivity gradients in reflectivity (Awaka et al. 1998; Steiner et al. 1995). The PR rain rate retrieval is described in Iguchi et al. (2000, 2009), which utilizes a combination of the surface reference technique (Meneghini et al. 2000) and the Hitschfeld and Bordan (1954) method to correct for attenuation before deriving the surface rain rates.

Analysis of precipitation characteristics are supplemented using the TRMM GV dual-polarized S-band KPOL located at the Kwajalein Atoll. The continuously scanning observing system provided by the KPOL radar is ideal for understanding the changes in precipitating systems in an oceanic setting, providing high temporal and horizontal resolution sampling of precipitating systems. The KPOL-derived TRMM 2A55 product provides stable calibrated reflectivities with a $1.5-\mathrm{km}$ vertical resolution and $2-\mathrm{km}$ horizontal resolution (Silberstein et al. 2008; Marks et al. 2009). KPOL rain rates (TRMM $2 \mathrm{~A} 53$ product) and convective/stratiform partitioning (TRMM $2 \mathrm{~A} 54$ product) are also used to aid the precipitation regime classification and to analyze variability in precipitation characteristics. For this work, KPOL data are observed over six wet season periods (September-December) from 2006 to 2011. The wet season months provide the majority of the regional precipitation at Kwajalein (Wolff et al. 2005) and coincide with the boreal winter months, where ENSOrelated precipitation anomalies are typically largest (e.g., Alexander et al. 2004; Chiodi and Harrison 2015).

Precipitating systems over the tropical oceans are categorized using data from the $2 \mathrm{~A} 25$ product following the methodology described in Elsaesser et al. (2010) for all TRMM orbits from 1998 to 2013. The classification separates precipitation into three precipitation regimes according to their level of organization. As described in Elsaesser et al. (2010), the regimes are created by inputting TRMM PR precipitation characteristics contained within a $1^{\circ} \times 1^{\circ}$ box centered along nadir PR pixels into a $k$-means clustering algorithm. The inputs include the fraction of precipitating convective echo-top heights $(\mathrm{ETH})$ less than $5 \mathrm{~km}$, fraction of convective ETH from 5 to $9 \mathrm{~km}$, fraction of convective ETH greater than $9 \mathrm{~km}$, mean convective rainfall, and the ratio of the mean convective to total mean rainfall. The $1^{\circ}$ region is large enough to statistically capture the distribution of convection, but also limits effects of scanning geometry by focusing toward nadir pixels. Further, while the $k$-means clusters are based on the predominant, deepest clouds, each $1^{\circ} \times 1^{\circ}$ region contains a spectrum of clouds with various echo-top heights and precipitation types (i.e., convective/stratiform rainfall). For the resulting $k$-means separated systems we adopt the definitions described by Elsaesser and Kummerow (2013), who define the three categories as shallow, typically warm rain precipitation with echo tops commonly below $5 \mathrm{~km}$; deep unorganized convection mixed with shallow congestus; and deep organized convection containing substantial amounts of deep stratiform rainfall and convective ETH commonly greater than $9 \mathrm{~km}$. The terms shallow, deep isolated, and organized precipitation regimes will be used henceforth in this paper to describe the level of organization of precipitating systems.

As in Henderson et al. (2017a), each precipitating regime is further sorted into cases containing 
predominantly convective or stratiform rainfall using PR defined precipitation types to understand which precipitation type drives the regime. This separation method was shown to better describe rain rate differences between TMI and PR estimates, providing a physical separation of where the main component of rainfall is originating and reduces the uncertainty that could be introduced by collocating each sensor to an individual footprint size. The study found that the collective information provided by a regime-based analysis provided improved representation of TRMM uncertainties between ENSO phases. Using the TRMM $\mathrm{PR}$ rain rates within the $1^{\circ}$ grid box the convective fraction of each precipitation regime is defined as the fraction of total rainfall contributed by convective rainfall. A predominately convective case is described where the convection precipitation fraction $>0.50$ and a stratiform case where the convective precipitation fraction is $<0.50$. TMI-retrieved surface rainfall contained within the collocated PR swath is matched to each $1^{\circ} \times 1^{\circ}$ domain along the TRMM orbit and mean rain rates from TMI and PR over each $1^{\circ} \times 1^{\circ}$ region are compared, where differences are defined as TMI minus PR rain rate estimates. Precipitating systems from the KPOL radar are identified using the same procedure applied to the KPOL radar reflectivity and rain rates from 2006 to 2011, which was successfully used previously to study rain rate sensitivity to precipitation regimes at Kwajalein in Henderson et al. (2017b).

To relate the precipitation features to their respective large-scale environments we utilize the European Centre for Medium-Range Weather Forecasts (ECMWF) interim reanalysis (ERA-Interim; Dee et al. 2011) gridded at $1^{\circ} \times 1^{\circ}$ resolution and 6-hourly temporal resolution. Environmental parameters of CAPE, SST, zonal wind profiles, and relative humidity are taken from the ERA-Interim reanalysis to compare with the precipitation regimes. The TRMM data are collocated spatially to the nearest ERA-Interim grid box and temporally to the closest time preceding the TRMM observation. Environmental properties are important factors when considering the level of organization in precipitating systems. Humidity fields have been shown to be accurate when compared to the Atmospheric Infrared Sounder (AIRS) and sounding data in Tian et al. (2010) and moisture retrievals with the Constellation Observing System for Meteorology, Ionosphere, and Climate (COSMIC) (Kishore et al. 2011). The comparisons show that systematic errors in ERA-Interim environmental properties are lower than those from other reanalysis datasets. For these reasons, the ERA-Interim reanalysis currently provides the best available dataset to compare environmental properties over the oceans over the period of the TRMM mission. To ensure that results in humidity are consistent, we include analysis using the methodology described by Masunaga (2013) that combines collocated TRMM data with the AIRS retrievals in order to observe the variability in the vertical structure of environmental moisture conditions associated with TRMM precipitating systems. For this work we use TRMM with AIRS satellite measurements of atmospheric moisture composited over El Niño and La Niña/neutral conditions in the Pacific $\left(15^{\circ} \mathrm{S}-15^{\circ} \mathrm{N}\right.$, $160^{\circ}-280^{\circ} \mathrm{E}$ ) from 2002 to 2009 . The composite procedure records the AIRS moisture data with respect to the overpass time difference between TRMM and AIRS, providing a continuous record of mean water vapor mixing ratio in hourly intervals for $72 \mathrm{~h}$ before and after TRMM observations of rainfall.

\section{Convective variability observed at the Kwajalein Atoll}

This study first investigates variability in the defined precipitation regimes using the KPOL radar located on the Kwajalein Atoll. While TRMM orbital data allow broad spatial observations of precipitation, regional measurements of individual precipitating regimes can be sporadic, particularly observations containing significant amounts of rainfall (Schumacher and Houze 2000). To better understand the variability in the convective populous, the high temporal resolution GV data from the Kwajalein KPOL radar site can be used as a starting blueprint for understanding ENSO-related variability of convection and its associated environmental properties. Precipitation anomalies during ENSO events are typically locked seasonally to the boreal winter months (Rasmusson and Carpenter 1982). We therefore observe variability occurring in the physical characteristics of the precipitating regimes from 2006 to 2011 during the wet season months (September-December) at the Kwajalein Atoll, a period when the majority of rain accumulation occurs and fully captures two El Niño and two La Niña events.

\section{a. Convective variability observed by the KPOL radar}

To begin highlighting ENSO-based variations in the extent and frequency of the precipitation regimes, SST and TMI-PR rain rate differences for each wet season are included in Table 1. To provide sufficient sampling, TMI rain rates within the PR swath are compared within a $5^{\circ} \times 5^{\circ}$ box surrounding the Kwajalein region. Precipitation properties occurring within the regimes for each wet season are presented in Table 2, including precipitation regime occurrence, rain extent, and 
TABLE 1. Mean SST anomaly compared to the TMI-PR difference (as a percentage) occurring over each wet season at Kwajalein from 2006 to 2011. Mean TMI-PR differences are calculated using all raining systems observed by TRMM in a $5^{\circ} \times 5^{\circ}$ region surrounding the atoll.

\begin{tabular}{lcccccc}
\hline \hline & 2006 & 2007 & 2008 & 2009 & 2010 & 2011 \\
\hline SST anomaly ( $\left.{ }^{\circ} \mathrm{C}\right)$ & +0.4 & -0.1 & -0.6 & +0.2 & -0.2 & -0.3 \\
$(\mathrm{TMI}-\mathrm{PR}) / \mathrm{PR}(\%)$ & $+9.1 \%$ & +1.8 & -6.4 & +10.7 & -12.0 & -2.9 \\
\hline
\end{tabular}

stratiform fraction. The raining extent is defined as the fractional areal coverage of radar-detected raining pixels within each $1^{\circ} \times 1^{\circ}$ box. Similar to TRMM observations discussed in Henderson et al. (2017a), when compared to La Niña wet seasons $(2008,2011)$ the two El Niño events $(2006,2009)$ exhibit higher occurrence of organized precipitation and precipitation system extent, which coincides with positive TMI-PR rain rate differences. It should be noted that wet seasons directly following El Niño events, when SSTs anomalies are negative, also exhibit large stratiform extent in organized rainfall; however, the frequency of occurrence in the organized regime is lower, suggesting that the higher SST anomalies may be important to help drive more frequent convection. Further, the El Niño periods contain the lowest occurrence of shallow precipitating systems, where the majority of rainfall occurs within deep and organized precipitation regimes. As shown in Fig. 1, stratiform rainfall also contributes more to the total rainfall during the warmer SST periods at the Kwajalein $\mathrm{GV}$ site, where there is a systematic shift toward more stratiform rainfall. La Niña time periods are generally influenced by isolated convection, smaller system size, and negative TMI-PR differences. In 2008, the majority of precipitating systems are identified as shallow precipitation regimes, whereas in 2011 there exists an increased occurrence of shallow and deep precipitation regimes compared to El Niño years. The observed shift toward more shallow and deep systems during La Niña is also accompanied by the lowest rainfall extent and stratiform extent across all precipitation regimes.

Analyzing the frequency and distribution of reflectivity with height provides further detail on the variability in vertical structure and possible microphysical processes in precipitating systems. Contoured frequency by altitude diagrams (CFADs) of KPOL reflectivities for convective and stratiform rainfall originating from deep isolated and organized precipitation regimes are shown in Fig. 2. While the physical properties of precipitation can differ from each other between the precipitation regimes (e.g., Henderson et al. 2017b), the overall observed changes in the vertical structure are similar between the deep and organized regimes and have been combined in the CFADs. The CFADs are
TABLE 2. Mean precipitation system characteristics in terms of system size and occurrence for each of the precipitation regimes observed by the KPOL radar during each wet season at the Kwajalein from 2006 to 2011.

\begin{tabular}{lrrrrrr}
\hline \hline & 2006 & 2007 & 2008 & 2009 & 2010 & 2011 \\
\hline Shallow & & & & & & \\
Occurrence (\%) & 44.1 & 50.2 & 53.2 & 44.4 & 50.2 & 48.2 \\
Rain extent (\%) & 3.1 & 2.9 & 2.5 & 3.2 & 3.8 & 2.8 \\
Stratiform extent (\%) & 1.7 & 1.5 & 1.4 & 1.8 & 1.7 & 1.5 \\
Deep & & & & & & \\
Occurrence (\%) & 34.7 & 34.3 & 28.7 & 33.5 & 31.0 & 35.9 \\
Rain extent (\%) & 16.7 & 13.8 & 10.6 & 10.7 & 12.9 & 10.2 \\
Stratiform extent (\%) & 5.1 & 4.6 & 3.9 & 4.5 & 4.7 & 3.7 \\
Organized & & & & & & \\
Occurrence (\%) & 21.2 & 15.5 & 18.1 & 22.1 & 18.8 & 15.9 \\
Rain extent (\%) & 40.1 & 39.4 & 31.7 & 36.0 & 36.6 & 33.4 \\
Stratiform extent (\%) & 33.7 & 27.8 & 18.6 & 26.3 & 26.8 & 24.6 \\
\hline
\end{tabular}

shown both for warmer SST wet seasons during El Niño (2006, 2009; Figs. 2a,b) and La Niña (2008, 2011; Figs. 2c, d). In general, CFADs between the precipitation types display the same vertical structure. Below the freezing level, $\sim 5 \mathrm{~km}$ as indicated by the bright band signature in the stratiform precipitation, the distribution of reflectivities is generally similar between the individual precipitation types. Differences, however, exist above this level. When observing the total frequency of observations as a function of height (Figs. 2d,e), the El Niño years contain a higher occurrence of radar observations above $5 \mathrm{~km}$ for both convective and stratiform precipitation. While the CFADs exhibit the general tilting structure with height, the warmer SST periods extend more vertically in the upper levels. This indicates that larger precipitation particles, or possibly more particles, are being lofted above the freezing level in convection and then being transported to the stratiform regions during these time periods. This evidence of deeper stratiform and convective extent is consistent with the colder cloud-top temperatures and echo-top heights observed by Masunaga et al. (2005) as well as in CloudSat observations (Li and Schumacher 2010).

\section{b. Environmental relationship to precipitation variability at Kwajalein}

Formation of MCSs with broad stratiform regions is largely dependent on the thermodynamic and moisture properties of the atmosphere as well as the strength of upper-level wind shear (Yuter and Houze 1998; Houze 1993, 2004). In this section ERA-Interim reanalysis fields are collocated to each precipitation regime for El Niño and La Niña events to better understand precipitation organization's relationship to the large-scale environment. As with the convective variability section above, we compare environmental properties at the 


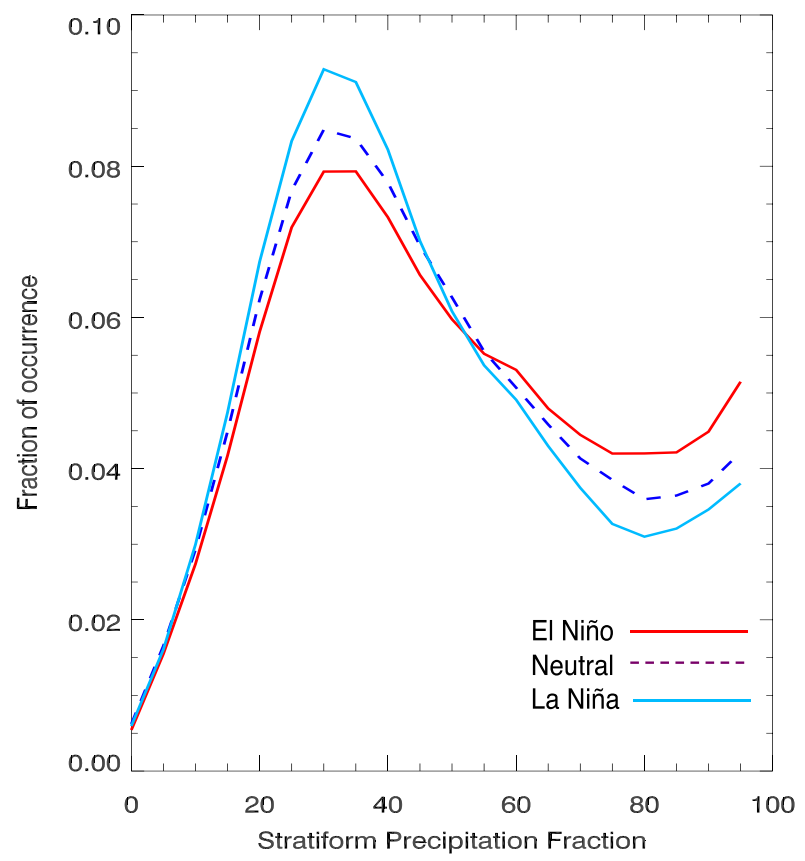

FIG. 1. Frequency distribution of the stratiform rain fraction as observed by the KPOL radar over three wet season periods based upon SST anomalies during each wet season defined as El Niño (2006, 2009), neutral (2007, 2010), and La Niña (2008, 2011).

Kwajalein Atoll for both phases of ENSO; warmer SST periods at Kwajalein contain significantly different occurrences of stratiform precipitation extent compared to the La Niña wet seasons (Table 2). Figure 3 illustrates zonal wind profiles and relative humidity profiles for each of the precipitation regimes categorized by El Niño and La Niña over the Kwajalein region, where the red and blue lines distinguish the El Niño and La Niña events, respectively. Mean SST, CAPE, and wind shear values for the organized precipitation regimes are also provided in Table 3.

Zonal winds vary little across the individual precipitation regimes, with easterly winds throughout the lower and middle levels and are slightly stronger during $\mathrm{La}$ Niña conditions. Each regime occurs in an environment with minimal midlevel shear $(850-500 \mathrm{mb})$, suggesting that stratiform precipitation formation in this region may be less reliant on shear and instead more reliant on convective rain frequency. This environment is common in the tropical oceans where broad stratiform regions are typically created and sustained through old and decaying convective cells (Houze 1997). Increased convection is supported by the higher SST and CAPE values found in the organized precipitation regimes during El Niño. While the lowerlevel and midlevel wind shear conditions vary little between the warm and cold SST events, large differences exist with upper-level wind shear $(500-200 \mathrm{mb})$. The influence of the Walker circulation is evident as upper-level wind shear strengthens during La Niña by nearly a factor of 2. It has been shown previously that strong upper-level wind shear can be detrimental to the formation of precipitating stratiform regions as the wind can transport ice particles farther, leading to more nonprecipitating anvil regions (Schumacher and Houze 2006; Li and Schumacher 2010).

For all precipitation regimes, the oceanic environment provides ample low-level moisture, resulting in marginal differences in the shape and magnitude of relative humidity profiles from the surface to $900 \mathrm{mb}$ (Fig. 3b). Significant differences, however, exist above this level between the warm and cold ENSO events; this is particularly noticeable near $400-500 \mathrm{mb}$ where there is an increase in moisture of $\sim 10 \%$ for organized precipitation during El Niño. Overall, there is a systematic increase in relative humidity at midlevels, which increases as a function of precipitating system organization, where the highest humidity values occur in organized precipitation regimes during El Niño time periods. This shift in precipitation is consistent with previous work, which demonstrated moistening of the atmosphere prior to periods of significant stratiform rainfall in the west Pacific and Indian Ocean (e.g., Sobel et al. 2004; Barnes and Houze 2013). The increased moisture occurring in organized precipitation implies that the precipitating stratiform regions are helping to moisten the environment; however, humidity profiles at Kwajalein during El Niño events are consistently more humid overall. Enhanced moisture is found throughout each of the precipitation regimes during El Niño events. The increased convective activity observed in this region could help feed moisture into the middle and upper levels, which will also help sustain an environment conducive to stratiform precipitation. This will be further discussed in section $4 \mathrm{~b}$.

\section{Relating TRMM TMI-PR differences to convective variability}

Henderson et al. (2017a) developed a conceptual model of expected biases in TMI and PR rainfall estimates for the precipitation regimes, which was used to discover the origins of TMI-PR differences. This model can be applied to discuss how regional variability in precipitation regimes leads to the observed variability in monthly mean TMI and PR rain rate estimates. In the GV analysis described in Henderson et al. (2017a), the TRMM PR rain rate estimates generally underestimated Kwajalein GV polarimetrically tuned rain rates across all precipitation regimes, with the highest biases originating from predominantly convective rainfall. TMI rain rates exhibit similar bias patterns within predominantly convective rainfall; however, the TMI 

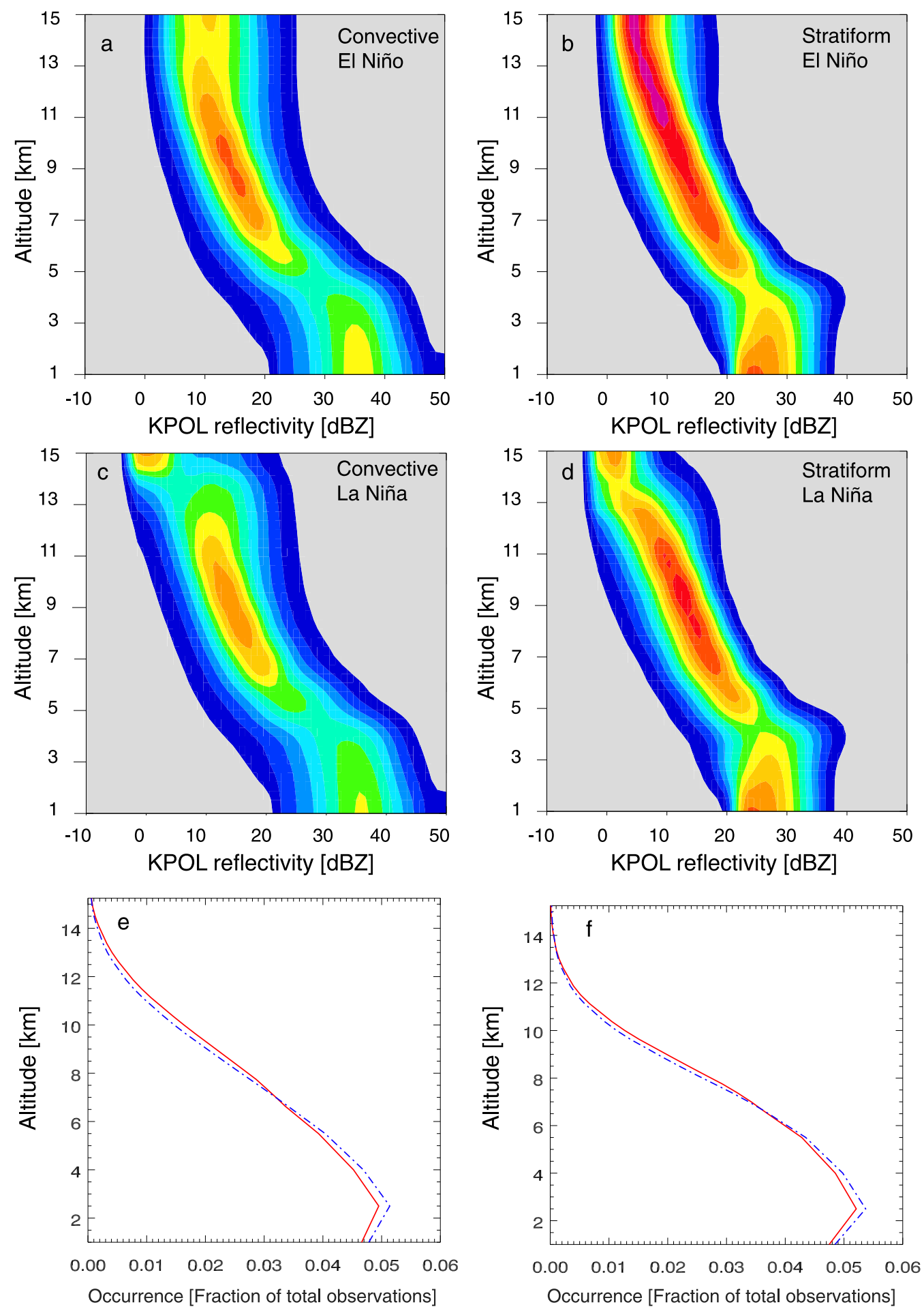

FIG. 2. Contoured frequency by altitude diagrams (CFADs) of reflectivity profiles observed at the KPOL radar occurring for deep isolated and organized precipitation regimes split by (left) convective rainfall and (right) stratiform rainfall. The CFADs are created over the (a),(b) El Niño $(2006,2009)$ wet seasons and (c),(d) for La Niña (2008, 2011) by binning by altitude every $750 \mathrm{~m}$ and reflectivities are binned in 1 -dB increments. (e),(f) Comparisons of normalized occurrence by altitude between El Niño (solid) and La Niña (dashed) conditions. 

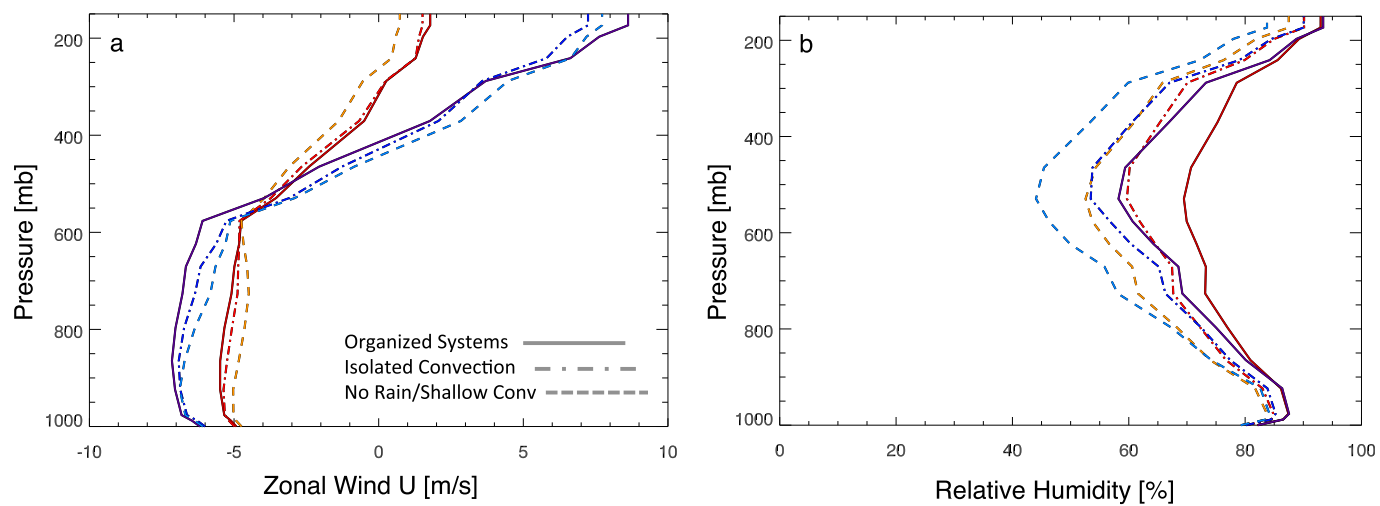

FIG. 3. (a) Zonal wind and (b) relative humidity profiles as a function of precipitation regime and ENSO phase from the Kwajalein Atoll radar. Included are organized regimes (solid), deep isolated regimes (dot dashed), and regimes with no rainfall or shallow convection (dashed). Each regime is shown during (red) El Niño from the 2006 and 2009 wet season and (blue) La Niña during the 2008 and 2011 wet seasons. Environmental data are based on spatially and temporally matched ERA-Interim reanalysis fields.

rain rates heavily overestimated Kwajalein GV estimates in precipitation regimes containing significant amount of stratiform precipitation. Elsaesser et al. (2010) described a self-similar nature observed in the precipitation regimes, therefore, we hypothesize that the TRMM bias patterns and TMI-PR rain rate differences will exhibit consistency across other oceanic regions as well.

\section{a. Convective variability over the tropical oceans}

When comparing only TMI and PR rainfall estimates, Henderson et al. (2017a) observed that the TMI retrieval struggled to differentiate convective and stratiform precipitation types, leading to underestimates compared to PR rain estimates in predominantly convective rainfall and overestimates in predominantly stratiform rainfall. These differences varied as a function of the observed precipitation regime. Therefore, regions displaying variability in TMI-PR differences are likely exhibiting a shift in precipitation properties. This information can be used to relate which precipitating systems are driving the TMI and PR rain rate responses during 1997/98 and 2009/10 El Niño events, the two strongest El Niño events during the TRMM record. According to the ground validation results described in Henderson et al. (2017a), these warm ENSO events should demonstrate increased frequency of organized precipitation in regions of positive SST anomalies. When comparing to the mean distribution of the precipitation regimes (Fig. 4), during these two El Niño events, the largest changes in precipitation regime occurrence is focused toward the equatorial Pacific (Fig. 5), which is a region coincident with the positive SST and surface convergence anomalies associated with El Niño (Kim and Yu 2012; Ratnam et al. 2012). In the central and east Pacific, there is a shift toward precipitation containing more stratiform rainfall, with the largest anomalies occurring in organized precipitation regimes.

To evaluate the impact of the precipitation variability during ENSO phases, differences between TMI and PR are shown for El Niño and La Niña time periods (Fig. 6), defined where the ENSO-3.4 index exceeds $\pm 0.5^{\circ} \mathrm{C}$. Henderson et al. (2017a) demonstrated that TMI-PR rain rate differences occurring during El Niño near the Kwajalein GV site were largely driven by a systematic shift toward more frequent organized precipitation systems characterized by large stratiform regions, which is also observed across the Pacific basin (Fig. 6f). Relative to the PR estimated rain rates, overestimation of rainfall by TMI is largest and most widespread in the

TABLE 3. Mean SST, CAPE, midlevel shear (800-500 mb), and upper-level shear (500-200 mb) for Kwajalein, the central Pacific, and east Pacific regions as a function of ENSO phase.

\begin{tabular}{lrr}
\hline & El Niño & La Niña \\
\hline Kwajalein & & \\
SST $(\mathrm{K})$ & 302.5 & 301.6 \\
CAPE $\left(\mathrm{J} \mathrm{kg}^{-1}\right)$ & 1470.5 & 1273.7 \\
Midlevel shear $\left(\mathrm{m} \mathrm{s}^{-1}\right)$ & 1.5 & 2.2 \\
Upper-level shear $\left(\mathrm{m} \mathrm{s}^{-1}\right)$ & 4.6 & 12.6 \\
Central Pacific & & \\
SST $(\mathrm{K})$ & 301.9 & 300.7 \\
CAPE $\left(\mathrm{J} \mathrm{kg}^{-1}\right)$ & 730.6 & 601.7 \\
Midlevel shear $\left(\mathrm{m} \mathrm{s}^{-1}\right)$ & 3.2 & 10.3 \\
Upper-level shear $\left(\mathrm{m} \mathrm{s}^{-1}\right)$ & 7.6 & 22.2 \\
East Pacific & & \\
SST (K) & 300.8 & 299.6 \\
CAPE (J kg & & 675.4 \\
Midlevel shear $\left(\mathrm{m} \mathrm{s}^{-1}\right)$ & 722.9 & 5.5 \\
Upper-level shear $\left(\mathrm{m} \mathrm{s}^{-1}\right)$ & 1.7 & 16.2 \\
\hline
\end{tabular}



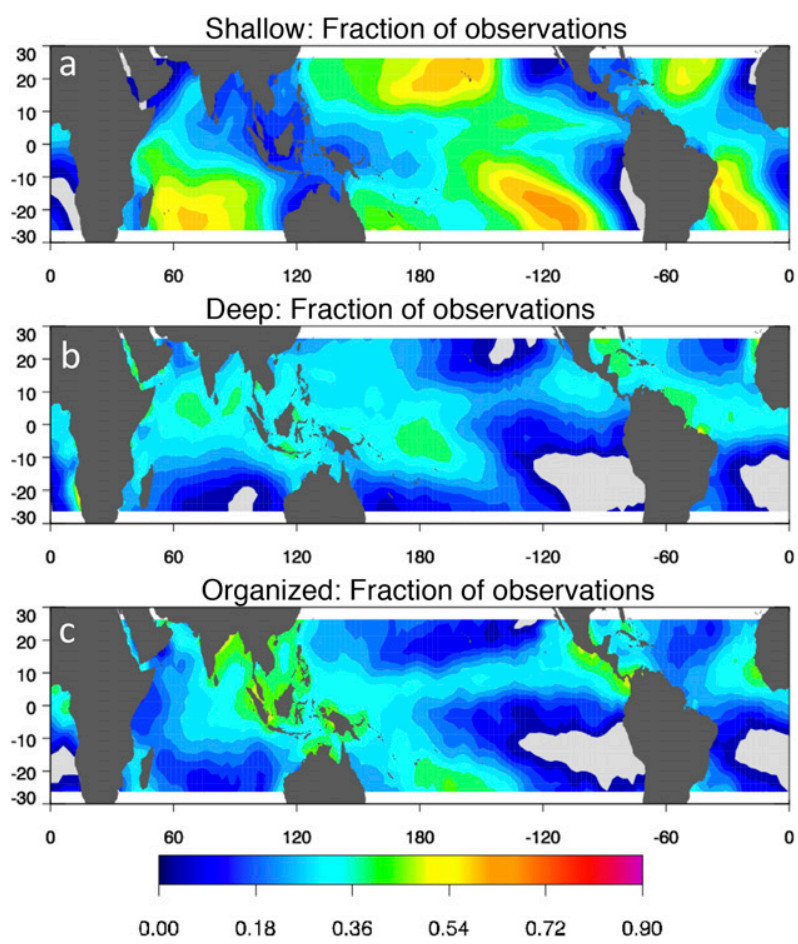

FIG. 4. Fractional occurrence for the (a) shallow, (b) deep, and (c) organized precipitation regimes.

central and east Pacific in the organized regimes and shallow regimes (Figs. 6b,f). The increase in organized regimes and stratiform occurrence during El Niño results in positive rainfall differences extending from the equatorial eastern Pacific to the central Pacific Ocean basins, which branches north and south toward the East China Sea and along the southern Pacific convergence zone. This pattern is nearly mimicked by the shallow precipitation regime (Fig. 6b), where the positive TMI$\mathrm{PR}$ differences occur where stratiform precipitation is predominant and negative where regimes are more dominated by convection. With the exception of the east Pacific, deep isolated precipitation contains predominately negative TMI-PR rain rate differences and exhibit less spatial variation between ENSO phases (Figs. 6c,d); deep regimes in this region are less frequent (Fig. 4).

During the El Niño events, the increased TMI overestimate in rainfall compared to PR is consistent with increases in stratiform precipitation associated with more organized precipitation, which is strongest in the central Pacific. This stratiform dependence can be further demonstrated by splitting the TMI-PR differences by precipitation type to display the convective and stratiform dependence in the rain rate differences (Figs. 6g,h). This is consistent with Seo et al. (2015) and Henderson et al. (2017a); the latter demonstrated that the magnitude of these TMI-PR differences increases as a function of precipitation regime. Similar to the Kwajalein region, the changes in precipitation anomaly patterns during El Niño show an increase in both system size and stratiform extent (Table 4). The largest tropical average increase $(7.6 \%)$ of stratiform extent, as identified by $2 \mathrm{~A} 25$ classification flags, is observed in organized precipitation regimes. This global signal is driven by changes in the central and eastern Pacific basins (not shown), where convective organized storms increase the most in frequency and stratiform area extent increases by nearly $20 \%$.

To help determine how the regional distribution of the regimes drives the ENSO-related tropics-wide rain rate estimates, the regimes responsible for the largest contribution toward TMI and PR rain rate differences are shown in Fig. 7. These regimes represent the different modes of organization that likely drive different patterns of variability found between TMI and PR monthly rain rate anomalies during El Niño (Fig. 7a) and La Niña (Fig. 7b) events. Shifts toward regimes that are typically positively biased (TMI $>$ PR; warm colors) will describe the regimes leading to time periods when TMI anomalies are positive, and shifts toward regimes that are typically negatively biased (TMI $<$ PR; cool colors) will describe the regimes leading to time periods when TMI anomalies are negative. The greatest differences between the ENSO phases are found in the west and central Pacific basins. The large swath of TMI rain rate overestimates are driven by a switch from deep isolated regimes to organized regimes containing large precipitating stratiform anvils (Fig. 7a). During La Niña, the negative differences found in the Atlantic, Indonesia region, and Indian Ocean are due to predominate rainfall from deep isolated precipitating regimes containing mostly convective rainfall (Fig. 7b). For both ENSO phases, the positive differences common to the east Pacific are related to shallow precipitating systems where most of the rainfall is defined as stratiform. This agrees with previous work, which describes the regional precipitation as predominantly shallow but somewhat organized systems (Liu and Zipser 2013; Chen and Liu 2016).

The regional variability found in each precipitation regime between ENSO phases is also evident when observing tropics-wide monthly rain rate anomalies. Comparisons of rain rate anomalies are focused from 2004 to 2011 to closely investigate the 2006/07 and 2009/ 10 El Niño events, which were both followed by La Niña. The TMI and PR monthly oceanic rain rate anomalies are derived by removing the climatological mean rain rate (observed from 2002 to $2013 ; 25^{\circ} \mathrm{N}-25^{\circ} \mathrm{S}$ ) from each monthly mean rain rate. While PR and TMI tropical rain rate anomalies differ in time (Fig. 8a), the contribution to the total rainfall for each precipitation regime is fairly 


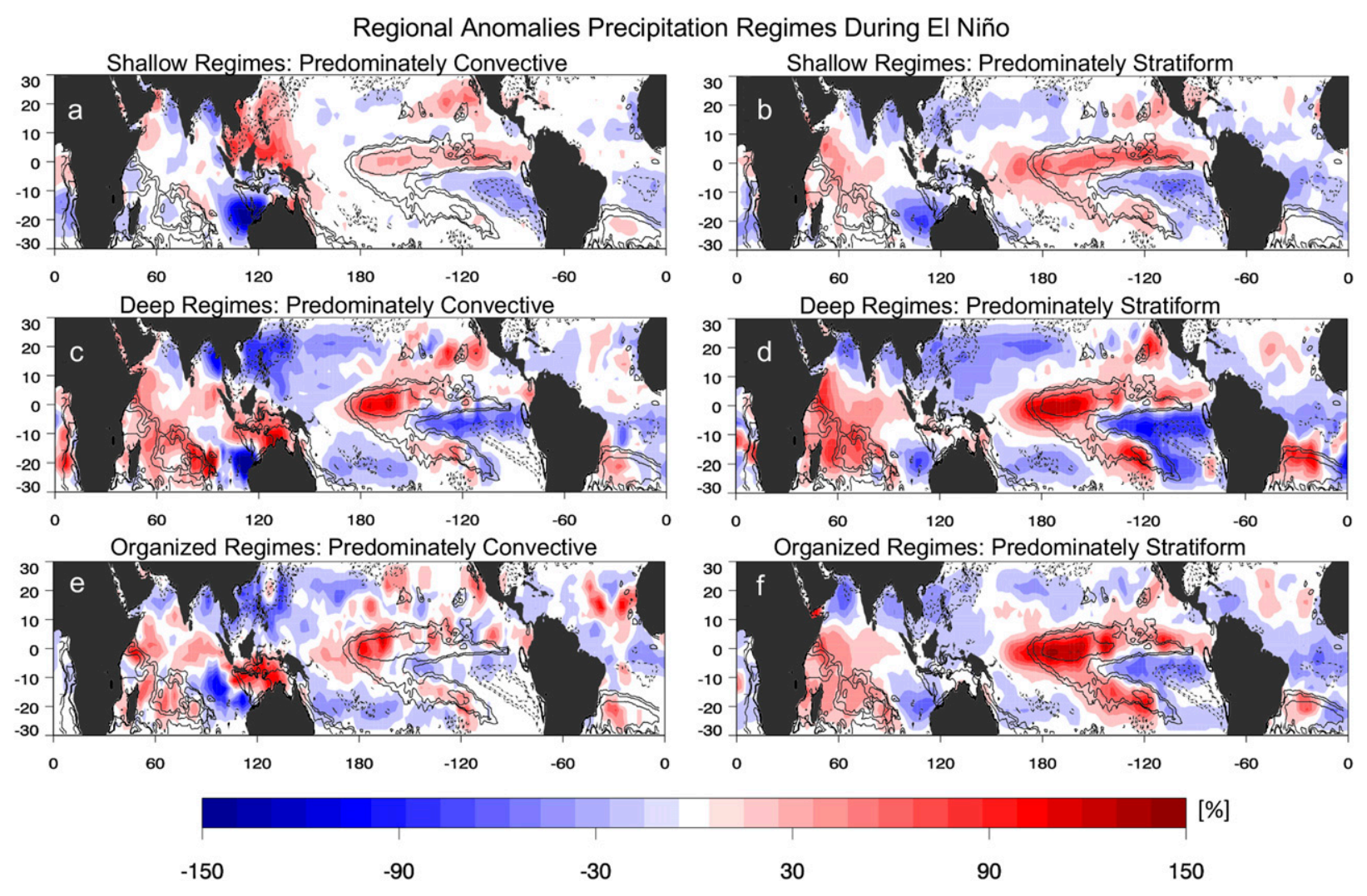

FIG. 5. Percent change in the regional distribution of the (a),(b) shallow, (c),(d) deep isolated, and (e),(f) organized precipitation regimes occurring during the 1997/98 and 2009/10 El Niño events compared to the 1998-2013 mean state. Regional maps are further split by convective fraction, showing (left) convective cases, where the convection precipitation fraction $>0.50$, and (right) stratiform cases, where the convective precipitation fraction is $<0.50$. ERA-Interim mean SST contours for the same time periods are overlaid where solid lines indicate positive anomalies and dashed indicate negative anomalies. SST contours are plotted at $1^{\circ} \mathrm{C}$ intervals starting at $\pm 0.5^{\circ} \mathrm{C}$.

consistent between TMI and PR (Fig. 8b), which show alternating periods dominated by deep isolated systems during La Niña and organized precipitation systems during El Niño. This pattern confirms the overall pattern found in Fig. 7, where the composited spatial patterns of regimes shifted from isolated regimes during La Niña to organized regimes during El Niño. This is further supported when observing the regime contributions to monthly rain rates over time. Figure 9 displays oceanic rainfall anomalies for TMI and PR deconstructed into their individual contributions from shallow, deep isolated, and organized precipitation regimes. Similar to Henderson et al. (2017a), the precipitation regimes containing predominantly stratiform rainfall describe the discrepancies found in the magnitude of the total oceanic rainfall anomaly between the rainfall retrievals. The stratiform rainfall regions in the organized and shallow precipitation regimes account for the majority of the TMI precipitation anomalies-a relationship less prominent in the PR estimates. This lower amplitude in the organized and shallow regimes results in lower PR rain rate anomalies occurring at the peak of El Niño
(Fig. 9b). This disparity is strengthened during the 2009/ 10 El Niño event when a sharp decrease in TRMM PR anomalies is due to differences in deep isolated convective precipitation regimes. The differences in deep isolated convection seem to be driven by more frequent deep convective rainfall over the Maritime Continent region during the 2009/10 central Pacific or Modoki El Niño event, which resulted in greater than normal convection in this region (Su and Jiang 2013).

\section{b. Environmental relationships in the central and east Pacific}

To expand upon the analysis above, environmental variables collocated to TRMM observations are observed within the central Pacific $\left(10^{\circ} \mathrm{S}-10^{\circ} \mathrm{N}, 180^{\circ}-\right.$ $\left.210^{\circ} \mathrm{E}\right)$ and eastern Pacific $\left(10^{\circ} \mathrm{S}-10^{\circ} \mathrm{N}, 230^{\circ}-260^{\circ} \mathrm{E}\right)$ ocean basins, regions where differences between TMI and PR are the largest during warm ENSO events. Collocated TRMM and ERA-Interim zonal winds and relative humidity conditions are displayed in Fig. 10, and mean SST, CAPE, and wind shear values are given in Table 3. ENSO-related differences in the vertical profile 

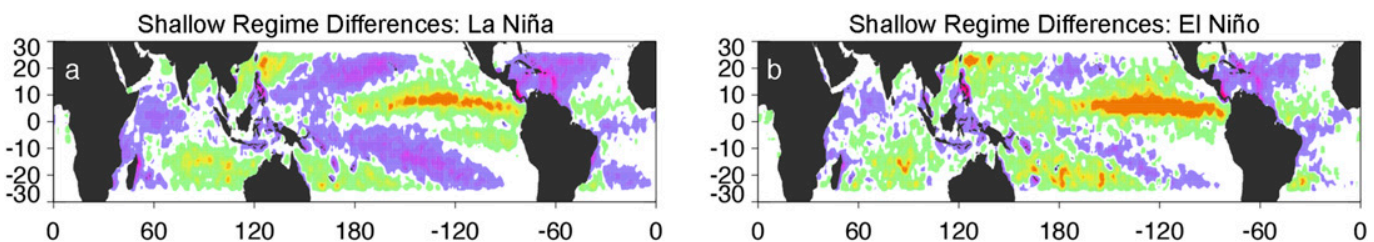

Deep Regime Differences: La Niña

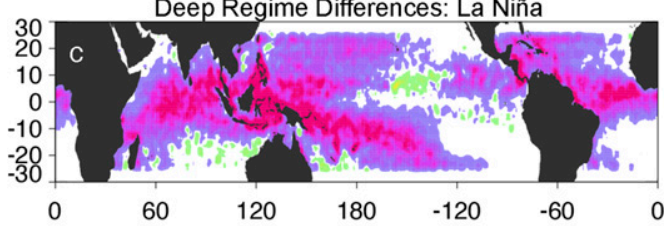

Deep Regime Differences: El Niño
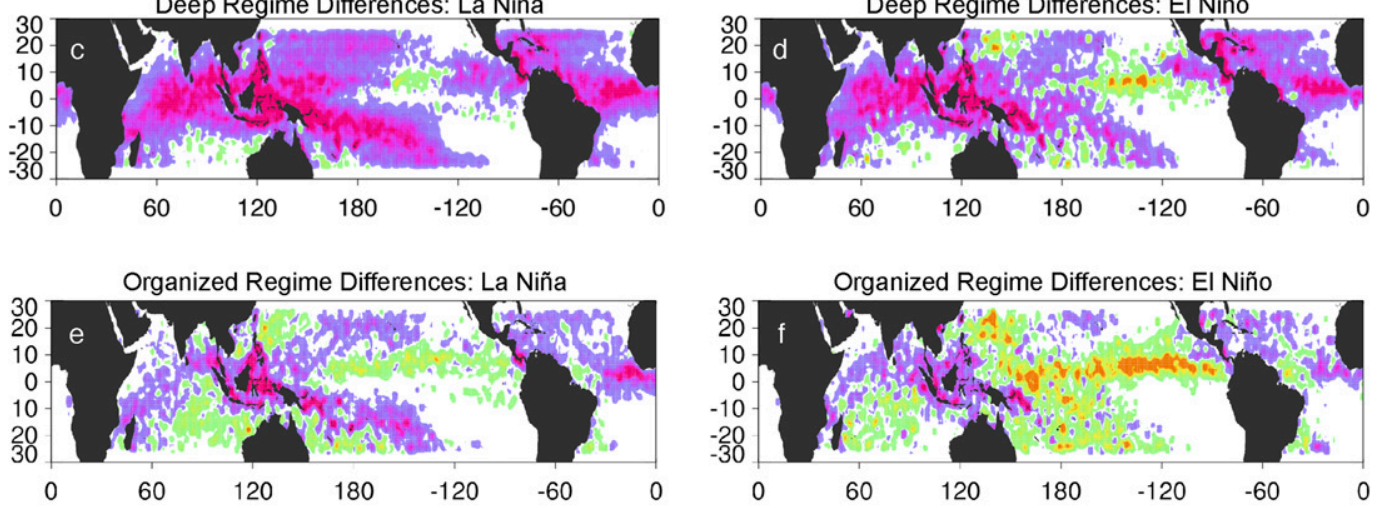

Precipitation Type Rain Rate Differences (TMI-PR)
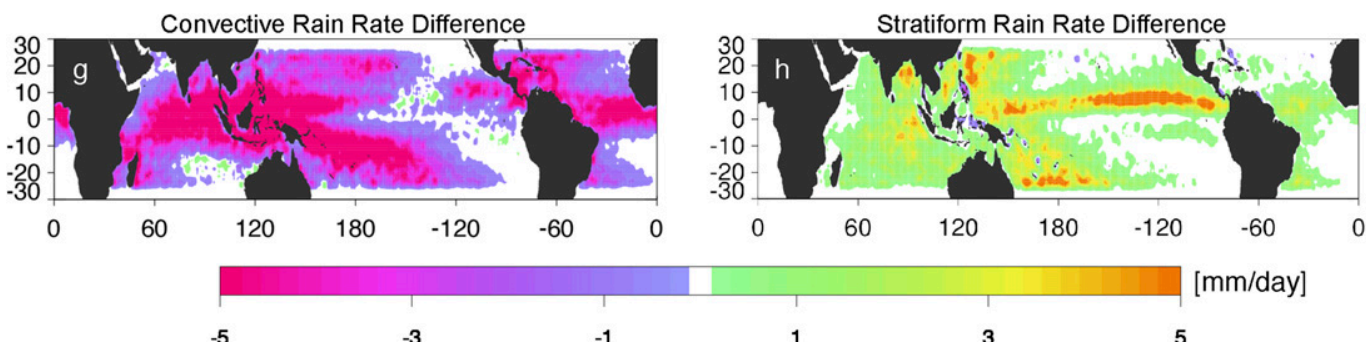

FIG. 6. TMI-PR rainfall differences $\left(\mathrm{mm} \mathrm{day}^{-1}\right)$ for the (a),(b) shallow, (c),(d) deep isolated, and (e),(f) organized precipitation regimes. Cases are split by (left) La Niña cases and (right) El Niño cases. (g),(h) All raining regimes compared to the TRMM post-boost climatological rain rates from 2002 to 2013, split into (left) convective cases and (right) stratiform cases. The difference maps were created by comparing collocated TRMM TMI and PR rain rates on a $1^{\circ} \times 1^{\circ}$ grid.

of zonal winds in the central and east Pacific are analogous to those observed at Kwajalein in section 3; however, the shape of the wind profiles differs from 1000 to $600 \mathrm{mb}$. During El Niño, winds remain easterly $\left(\sim 5 \mathrm{~m} \mathrm{~s}^{-1}\right)$ throughout the lower and middle troposphere. During La Niña, the easterly winds reach a maximum around $900 \mathrm{mb}$ and then weaken with height resulting in a large increase in zonal winds from 500 to $200 \mathrm{mb}$ aloft. The central and eastern Pacific basins are characterized by this sharp increase in winds (strengthening westerlies) near $600 \mathrm{mb}$, where the upper-level wind shear increases from $7.6 \mathrm{~m} \mathrm{~s}^{-1}$ during El Niño to $22.2 \mathrm{~m} \mathrm{~s}^{-1}$ during La Niña in the central Pacific. Not only is this change uniform across the precipitation regimes, but in general the upper-level shear increases as the precipitating regimes become more isolated and shallow.
Similar to the Kwajalein results, there exists little variability in the regional distribution of relative humidity within the lower troposphere and the largest discrepancies in moisture occur above $800 \mathrm{mb}$; the humidity values during La Niña slope toward drier conditions. This divergence in moisture is consistent for all of the precipitation regimes, which exhibit systematic increases in moisture as a function of system organization. Overall, the Kwajalein region exhibits the largest differences in humidity at midlevels near $500 \mathrm{mb}$; however, the central and east Pacific basins contain larger moisture disparities between ENSO events in the lower troposphere. The largest variability in moisture occurs within the eastern Pacific basin. In the east Pacific, the moisture minimum is lower in altitude during La Niña where relative humidity reaches a minimum around 


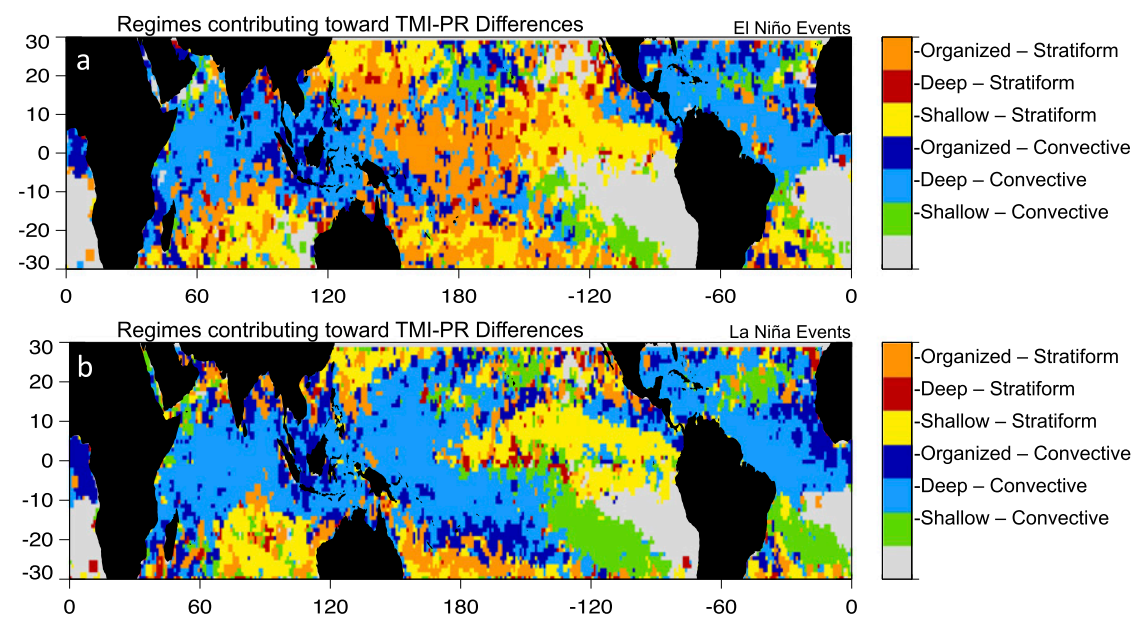

FIG. 7. Primary precipitation regime responsible for the TMI-PR differences gridded at $1^{\circ}$ resolution occurring during (a) El Niño and (b) La Niña conditions.

$600 \mathrm{mb}$ before increasing again in the upper troposphere. In contrast, during El Niño each regime reaches a minimum near $500 \mathrm{mb}$ and then remains nearly constant with height. These drier midtropospheric conditions in the east Pacific have been shown to be associated with more shallow organized precipitation (Chen and Liu 2016) that are dynamically forced by regional SST gradients (Back and Bretherton 2009; Back et al. 2017).

Composite analysis with collocated TRMM and AIRS-retrieved water vapor and relative humidity (Masunaga 2013) supplements our understanding of the humidity differences occurring before and after precipitation occurrence at time zero (Fig. 11). TRMM and AIRS data from 2002 to 2009 are composited in space and time over the Pacific Ocean $\left(15^{\circ} \mathrm{S}-15^{\circ} \mathrm{N}, 160^{\circ}\right.$ $280^{\circ} \mathrm{E}$ ) and separated monthly into La Niña/neutral and El Niño based on the ENSO-3.4 index for highly

TABLE 4. Percentage of mean rainfall fraction as well anomalies in rainfall fraction are provided for El Niño and La Niña occurring from 2002 to 2013. Percentages are defined as the total number of raining pixels detected by PR divided by the total number of pixels in a precipitation regime grid box.

\begin{tabular}{lccr}
\hline \hline & Stratiform & Convective & All \\
\hline Shallow regime & & & \\
Mean & 4.5 & 2.1 & 6.6 \\
El Niño & +4.0 & +3.5 & +4.0 \\
La Niña & -2.7 & +1.1 & -1.4 \\
Deep isolated regime & & & \\
Mean & 9.9 & 6.2 & 15.1 \\
El Niño & +3.2 & +3.9 & +4.8 \\
La Niña & -2.8 & -1.6 & -2.7 \\
Organized regime & & & \\
Mean & 27.2 & 7.8 & 35.0 \\
El Niño & +7.6 & -0.5 & +7.1 \\
La Niña & -0.1 & -0.1 & -0.4 \\
\hline
\end{tabular}

organized systems as identified in Masunaga (2013). Removing the mean background moisture state (defined as the first and last $12 \mathrm{~h}$ of all data in composite process) illustrates where moisture has been added into the region (positive anomalies). The temporal composite analysis confirms that increased moisture conditions exist in the middle and upper levels before the initiation of an organized system during El Niño compared to La Niña. Figure $11 \mathrm{~b}$ indicates that this increased humidity might relate to increased transport of moisture to the upper levels of the troposphere during El Niño conditions. Both ENSO phases demonstrate lower-level moistening in the atmosphere before the precipitation occurrence at time zero. The El Niño composites illustrate that this moistening reaches deeper into the free troposphere, suggesting that deeper convection occurring more frequently during warm ENSO events. This upper-level moistening is echoed in relative humidity profiles (Fig. 11c) well before the initiation of the organized precipitation event where higher moisture levels are found above $600 \mathrm{mb}$.

Based on the results above, the increased occurrence of stratiform precipitation observed during El Niño can be related to changes in large-scale environment. In the Pacific basins, an increase in stratiform precipitation is accompanied by increased environmental humidity in the middle and upper troposphere during warm events along with a weakening in upper-level wind shear. The warmer SSTs and CAPE during El Niño supports the observed increased occurrence in deep convective precipitation. This increased convective activity may be important for transporting moisture in the upper levels to help sustain stratiform precipitation regions. On the opposite end, the drier upper atmosphere and increased mid- and upper-level shear during La Niña could act to 

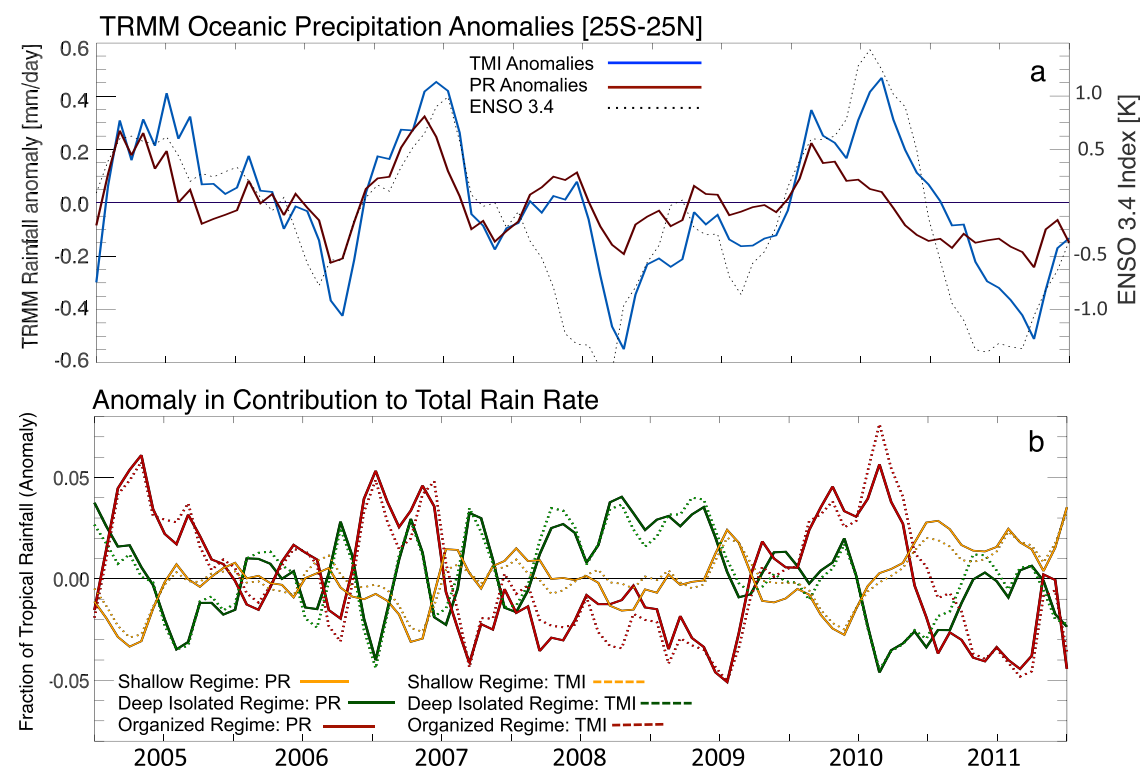

FIG. 8. (a) Time series of tropical mean oceanic rainfall anomalies $\left(25^{\circ} \mathrm{S}-25^{\circ} \mathrm{N}\right)$ from collocated TRMM TMI and TRMM PR rainfall products with the ENSO-3.4 index (dotted) included for reference. (b) Time series in the anomalies of shallow, deep isolated, and organized precipitation regimes contribution to the total rain rate for TRMM TMI (solid) and TRMM PR (dashed) rain rates.

enhance dry air entrainment and transport hydrometeors further from the convective sources, which might inhibit stratiform precipitation growth. This would result in a decreased occurrence in organized precipitation, thus making deep isolated convection the dominant source of precipitation and the primary contributor to TRMM rain rates over the oceans and the negative differences observed between the TMI-PR rain rates.

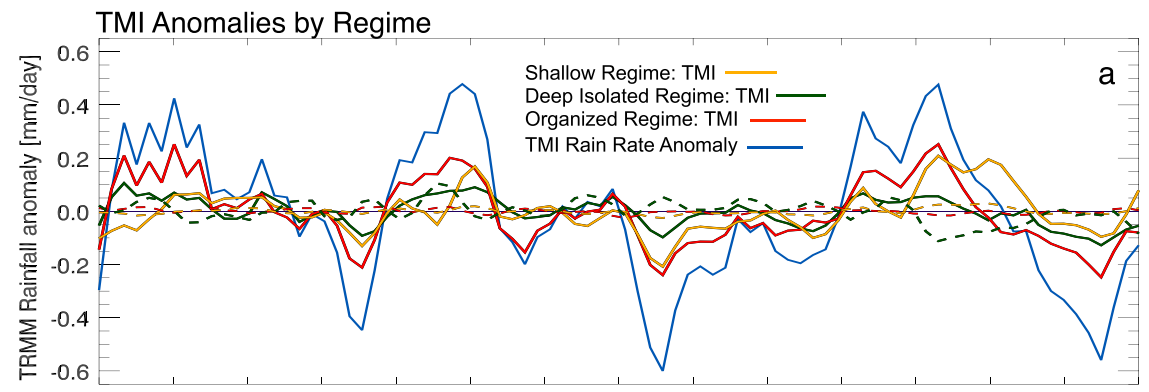

PR Anomalies by Regime

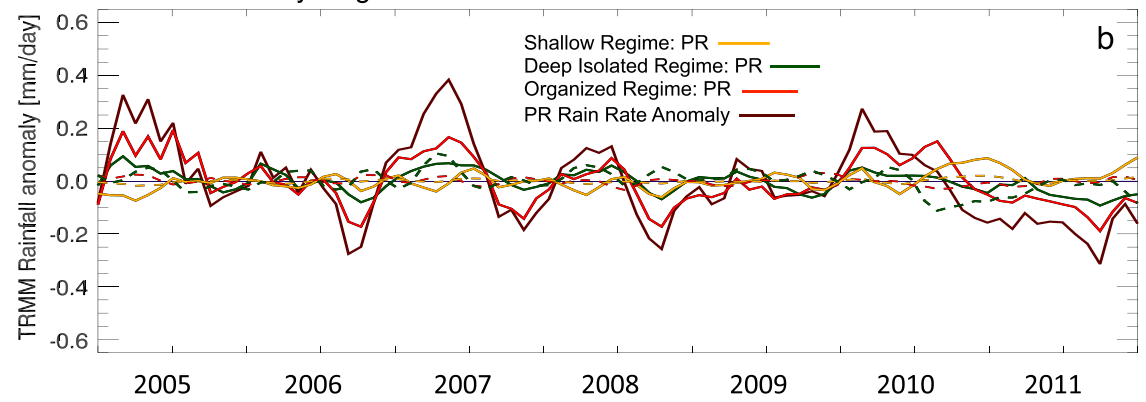

FIG. 9. Contributions to the (a) TMI and (b) PR rainfall anomalies for each precipitation regime over the tropical oceans split into convective (dashed) and stratiform (solid) cases. Total rainfall for TMI is shown in blue, and total rainfall for PR is shown in dark red. 

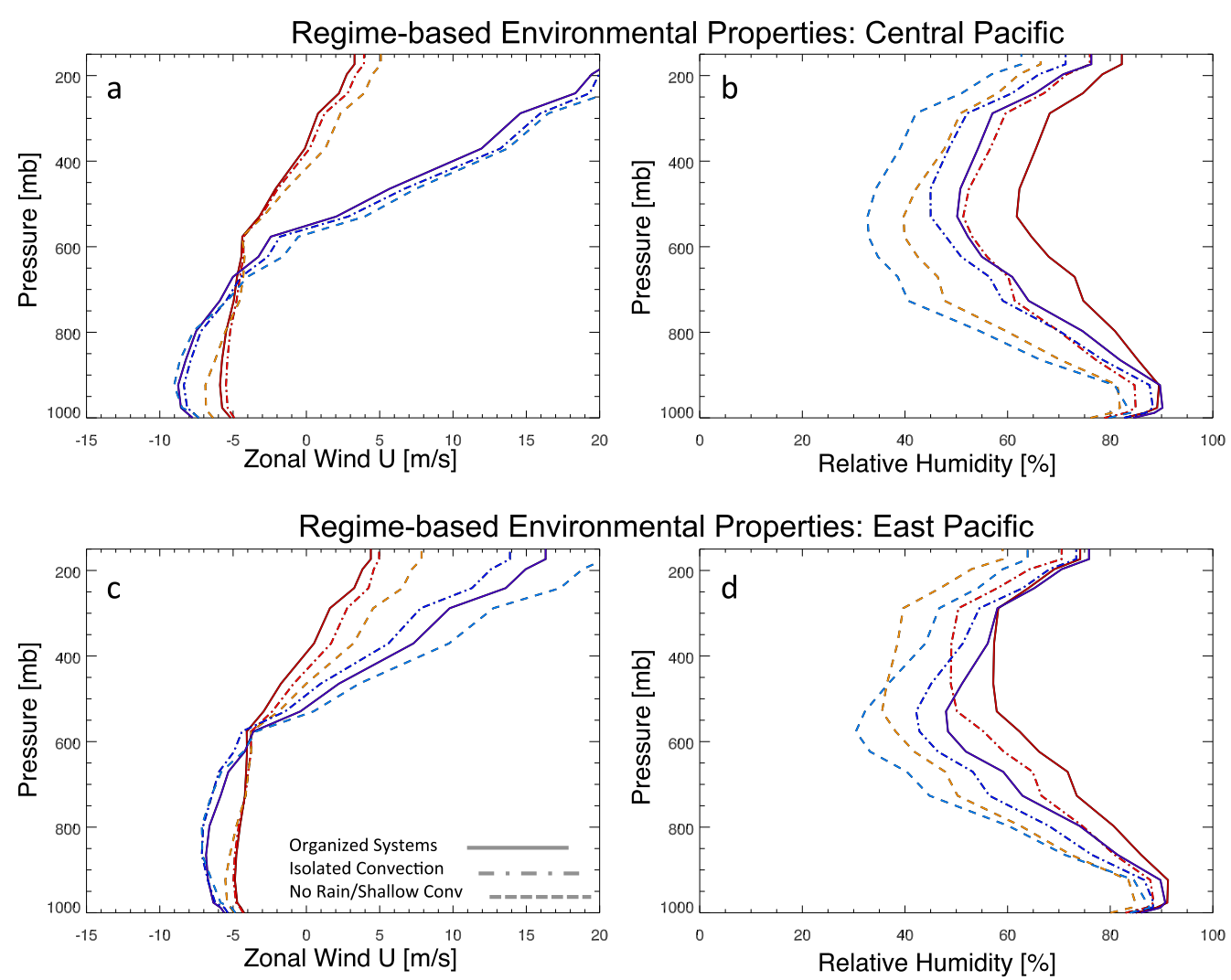

FIG. 10. (a) Zonal wind and (b) relative humidity profiles as a function of precipitation regime and ENSO phase from the (top) central Pacific and (bottom) east Pacific. Included are organized regimes (solid), deep isolated regimes (dot dashed), and regimes with no rainfall or shallow convection (dashed). Also included are MCSs observed in the TRMM RPF dataset (long dashed). Each regime is shown during El Niño and La Niña (red and blue, respectively) categorized using a $0.5^{\circ} \mathrm{C}$ threshold from the ENSO-3.4 index. Environmental data are based on spatially and temporally matched ERA-Interim reanalysis fields.

\section{Tropical precipitation sensitivity to SST}

Using GV from KPOL radar located on the Kwajalein Atoll, Henderson et al. (2017a) determined that precipitation regimes exhibited distinct bias patterns, which explained the majority of TMI-PR differences in a region surrounding the Kwajalein Atoll. In this section we apply the bias corrections described in Henderson et al. (2017a) to the precipitation regimes across the tropical oceans. This process will aid in a better understanding of the mechanisms responsible for the observed rain rate differences in the interannual variability of oceanic precipitation and help constrain our observational estimates in precipitation variability. The advantage of the Elsaesser et al. (2010) classification lies in the fact that the convective systems identified are found to be self-similar in nature across the tropical oceans, and as shown thus far the validation statistics seem to extend to other oceanic regions observed by TRMM. For reference, the GV-based biases from Henderson et al. (2017a) are displayed in Table 5.
The regime-based correction was applied to the TMI and PR rain estimates for the TRMM post-boost period from 2002 to 2013. Comparing the results shown in Fig. 12 with the original TMI-PR difference maps in Fig. 6, regional biases are still visible; however, the differences are reduced over several notable areas. First, the large positively biased regions in the central and eastern Pacific are greatly decreased, where TMI rainfall was decreased as a result of the retrieval significantly overestimating stratiform precipitation compared to the KPOL radar. Further, differences corresponding to deep isolated precipitation regimes in the Indian Ocean are reduced and the residual rain rate differences appear more or less randomly dispersed. Larger residual differences remain for deep isolated regimes occurring in the Maritime Continent region and precipitating systems advected off the western coast of Africa into the Atlantic basin. Residual differences also exist in the central Pacific and east Pacific in the regions where predominantly stratiform rainfall is observed. In 

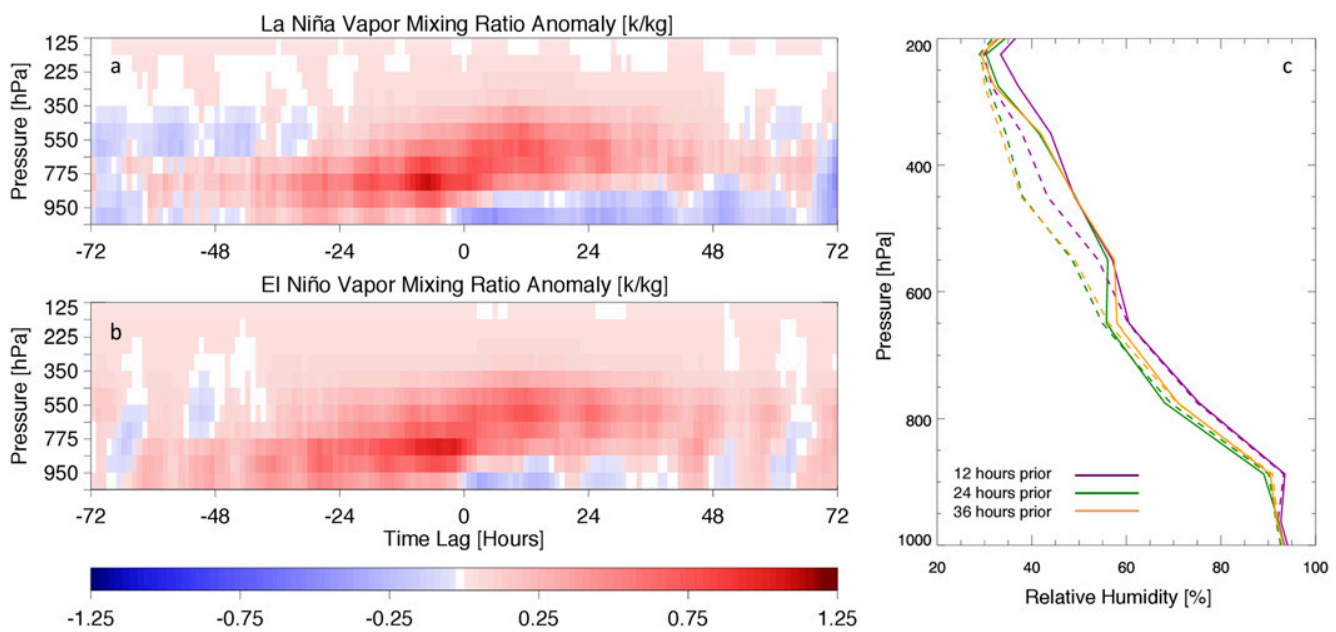

FIG. 11. Using the methods of Masunaga (2013), the time-pressure cross section of large-scale mean vapor mixing ratio $\left(\mathrm{g} \mathrm{kg}^{-1}\right)$ during (a) El Niño and (b) La Niña in composite space for highly organized systems occurring from 2002 to 2009 . The anomalies are created by subtracting the background state defined as the mean of the first and last $12 \mathrm{~h}$ for all cases. (c) Comparison of mean relative humidity profiles from El Niño (solid) and La Niña (dashed) 12-36 $\mathrm{h}$ before the occurrence of the organized precipitation.

general, the regime-based corrections result in an overall reduction in TMI-PR differences in most regions. Regions with overcorrection can result in larger differences, such as observed in the central Pacific for deep regimes as well as near the subtropics for deep and organized regimes in the Pacific basin.

The regional improvements in TMI-PR differences also result in changes in the time series of tropical mean precipitation anomalies (Fig. 13). In general, the applied correction increases $\mathrm{PR}$ rain rates over the tropical oceans rainfall due to the PR rainfall being underestimated across all precipitation regimes. By increasing rain rates where PR generally underestimated, the PR rain rate anomalies display increased magnitude in interannual rain rate anomalies more in line with the radiometer-based estimates of TMI and GPCP, particularly during El Niño when the precipitation is more frequent. While the magnitudes of TMI biases are higher, the biases are both positive and negative, leading to the peaks of TMI anomalies being decreased slightly. PR rain rates still drop off sharply during the 2009/10 El Niño, which seems to correspond to differences in deep isolated regimes occurring in the Maritime Continent and African coast regions. The Maritime Continent region is largely impacted by land-based orography, which can be difficult for radiometer-based estimates (e.g., Shige et al. 2013), and precipitating systems off the African coast are largely land-based rainfall transported over the oceans. For these regions it is likely that the ocean-based bias corrections obtained from Kwajalein might not be fully representative. When constraining the region to the Pacific basin $\left(160^{\circ}-280^{\circ} \mathrm{E}\right)$, the TMI and
PR rain rate anomalies converge toward each other and are in close agreement (Fig. 13b).

To understand how these corrections can help constrain the precipitation relationship to tropical SST variability, the mean monthly rainfall estimates from TRMM TMI and PR are compared to the mean tropical SST $\left(25^{\circ} \mathrm{S}-25^{\circ} \mathrm{N}\right)$ in Fig. 14 . Similar to previous work (e.g., Wang et al. 2008), before the correction the TMI rain rates are positively correlated with mean ocean SST, and the PR rain rates show little correlation with SST with a nearly flat relationship. GPCP is also positively correlated, but the sensitivity with SST is lower compared to the slope of TRMM TMI. The TMI and GPCP sensitivities are higher than reported previously; however, the radiometer precipitation and SST relationships are in line with more current values derived from TRMM version 7 products (R. Adler 2016, personal communication). When the TRMM bias correction is applied both of the TMI and PR sensitivities

TABLE 5. Bias statistics, as derived in Henderson et al. (2017a), between the TRMM PR and TMI rain rate estimates compared to the dual-polarized rain rates estimates at the Kwajalein GV site as a function of convective regime. Values are first compared for convective cases (convection fraction $>0.50$ ) and then for stratiform cases (convection fraction $<0.50$ ).

\begin{tabular}{lcccc}
\hline \hline Convective & All & Shallow & Deep isolated & Organized \\
\hline PR bias (\%) & -22.4 & -12.8 & -23.4 & -26.1 \\
TMI bias (\%) & -32.2 & +5.5 & -37.8 & -30.3 \\
Stratiform & All & Shallow & Deep isolated & Organized \\
PR bias (\%) & -6.1 & -11.4 & -8.4 & -2.6 \\
TMI bias (\%) & +27.9 & +25.5 & +8.1 & +33.4 \\
\hline
\end{tabular}



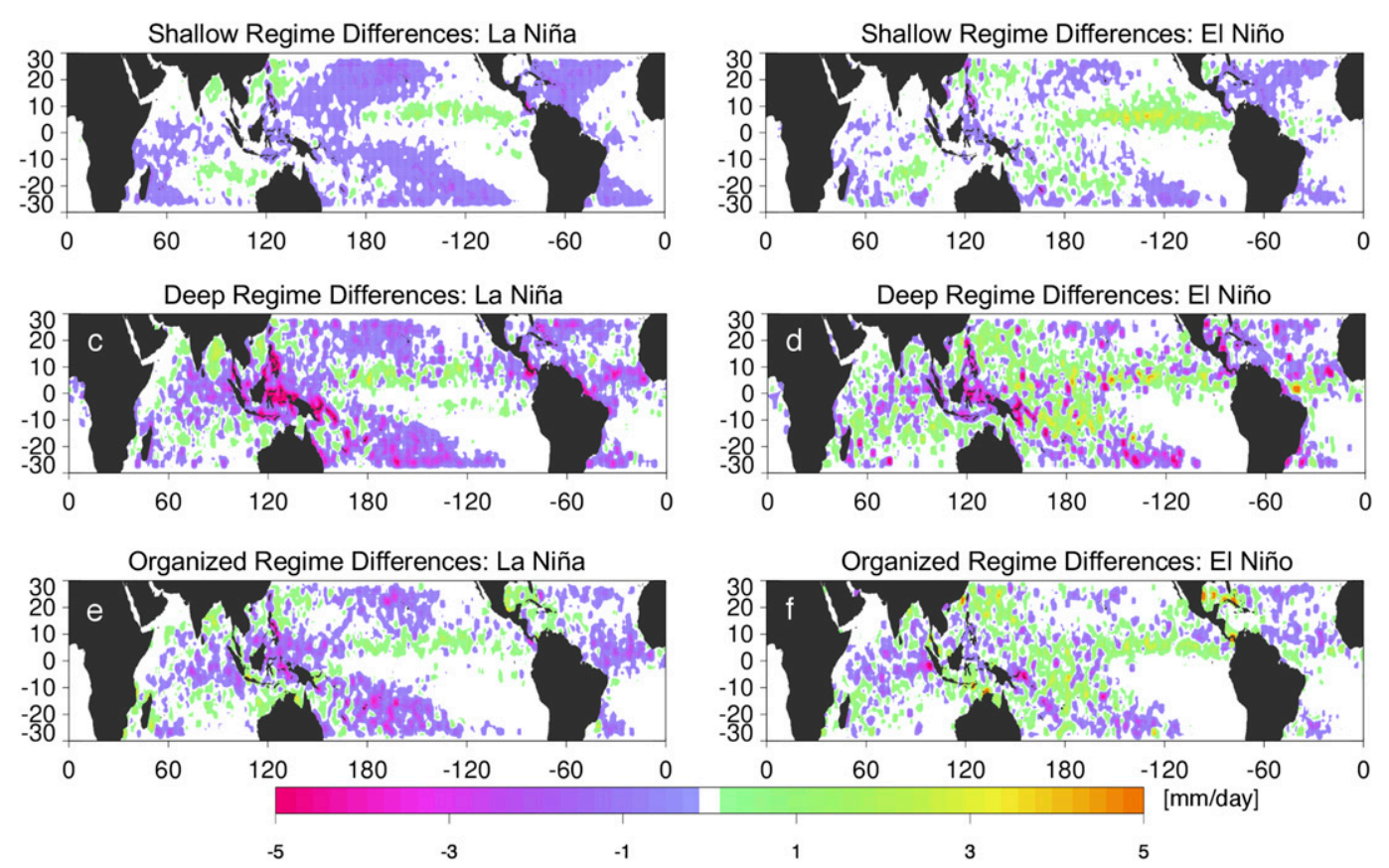

FIG. 12. TMI-PR rainfall differences $\left(\mathrm{mm} \mathrm{day}^{-1}\right)$ after the application of the bias correction described in Henderson et al. (2017a) for the (a),(b) shallow, (c),(d) deep isolated, and (e),(f) organized precipitation regimes compared to the TRMM post-boost climatological rain rates from 2002 to 2013. Cases are split into (left) La Niña and (right) El Niño cases.

converge toward the GPCP results (Fig. 14b). Over the tropical oceans, the TMI (GPCP) rainfall data exhibit similar responses to SST with changes of $17.5 \%{ }^{\circ} \mathrm{C}^{-1}$ $\left(15.1 \%{ }^{\circ} \mathrm{C}^{-1}\right)$. The increased rain rates in the $\mathrm{PR}$ rainfall increases the sensitivity from $4.4 \%$ to $9.7 \%{ }^{\circ} \mathrm{C}^{-1}$, converging toward the microwave radiometer-based rain rate relationships with SST.

\section{Summary and conclusions}

This work utilizes distinct self-similar precipitation regimes observed across the tropical oceans to characterize the ENSO impact of the regional precipitating cloud population on interannual rain rate anomalies estimated from TRMM TMI and PR. A combination of ground validation data and TRMM orbital data is used to observe changes in precipitation organization, precipitating system characteristics, and their respective large-scale environments. Precipitation variability is observed by categorizing TRMM rainfall using defined self-similar precipitation regimes following the methods of Elsaesser et al. (2010). We have shown that the spatial coverage of each precipitation regime varies significantly between the El Niño and La Niña ENSO phases, which can have significant impacts on the rainfall responses observed in the TMI and PR retrievals; these are particularly notable within the Pacific basin where
SST anomalies are most prevalent. Discrepancies in the ENSO-related interannual variability of rainfall are driven by systematic shifts in the precipitation state. The magnitude of the precipitation response to ENSO was found to be related to observed shifts from tropics-wide occurrence of more isolated deep convection during La Niña toward more organized rainfall occurring over the central and east Pacific during El Niño.

Over Kwajalein, organized precipitation regimes were found to be more frequent during El Niño with larger and deeper stratiform extent. Similarly, in the equatorial Pacific organized precipitation regimes become the dominant source of precipitation during El Niño with greater amounts of the rainfall classified as stratiform rain. These features are also observed in the east Pacific where a large number of these systems are shallower in nature related to the regional forcing of convection (Back and Bretherton 2009). The increased moisture in the upper levels during El Niño, however, provides evidence of more frequent deep convection in this region. The increased stratiform precipitation is positively biased for TMI rainfall estimates and seems to drive the majority of the discrepancies between TMI and PR. TMI consistently underestimates relative to PR rain rates in the regions of the west Pacific and Indian Ocean basins where the deep isolated convection is most prevalent and varies less between the ENSO phases. 


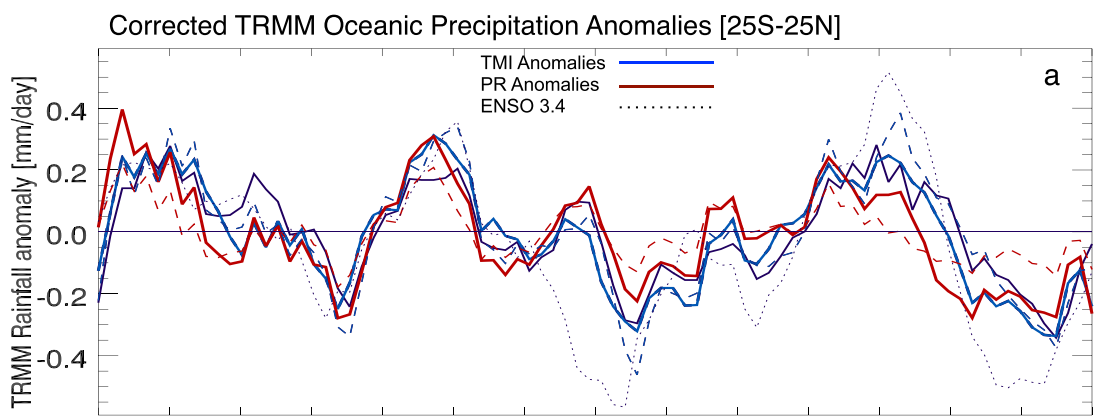

Corrected TRMM Oceanic Precipitation Anomalies [25S-25N; 160E-280E]

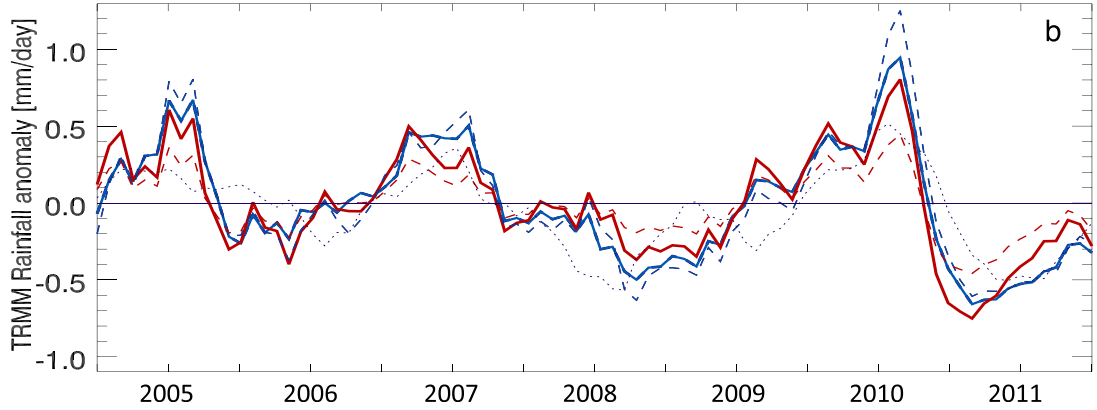

FIG. 13. (a) Time series of tropical mean oceanic rainfall anomalies $\left(25^{\circ} \mathrm{S}-25^{\circ} \mathrm{N}\right)$ from collocated TRMM TMI and TRMM PR rainfall products after the application of a bias correction described in Henderson et al. (2017a). Rain anomalies (dashed) before correction are included for comparison. (b) As in (a), but within a region covering only the west, central, and east Pacific basin $\left(160^{\circ}-280^{\circ} \mathrm{E}\right)$. The ENSO-3.4 index (dotted) is included for reference in both panels.

Although the contribution of deep isolated precipitation is reduced overall during El Niño, during the 2009/10 Modoki El Niño deep isolated precipitation increased over the Maritime Continent region, leading to larger discrepancies observed during this time period.

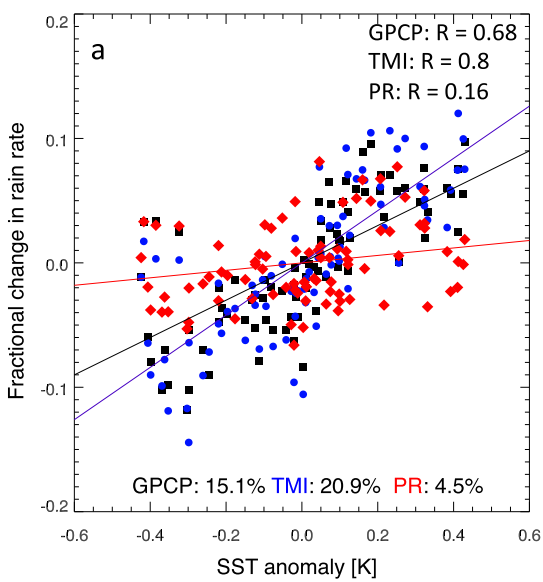

The increased stratiform rainfall occurs in regions where convective frequency is increased and where there are systematic increases in middle- and upper-level relative humidity. Midtropospheric relative humidity dramatically increases as a function of convective

FIG. 14. Scatterplot of the fractional change in (a) TRMM and GPCP precipitation anomalies as a function of SST anomalies $\left({ }^{\circ} \mathrm{C}\right)$ and (b) TRMM corrected precipitation anomalies and GPCP precipitation anomalies compared to SST anomalies over the tropical oceans $\left(25^{\circ} \mathrm{S}-25^{\circ} \mathrm{N}\right)$. Each panel includes the retrieval percentage of rain rate increase per ${ }^{\circ} \mathrm{C}$. Correlations between the rain rates and SSTs are included for each sensor. 
organization; however, moisture during El Niño is consistently higher for all precipitation regimes compared to La Niña. AIRS analysis suggests that this increased moisture is consistent throughout the midtroposphere well before the occurrence of organized convective events, where water vapor is transported deeper into the troposphere compared to La Niña. Barnes and Houze (2013) demonstrated that TRMM observed precipitation during the MJO in the Indian and west Pacific basins exhibited a large decrease in occurrence of broad stratiform regions associated with decreases in midtropospheric humidity and strong mid- or upper-level shear. The occurrence of more isolated convection during La Niña is associated with drier conditions and increased mid- and upper-level wind shear related to shifts in the Walker circulation. The increased shear and decreased humidity is likely a less favorable environment for stratiform precipitation, where hydrometeors can be transported farther from the convective sources and drier air can be entrained further inhibiting the stratiform growth.

Understanding precipitation regime regional variability helps constrain observational relationships between the tropical oceanic rainfall and sea surface temperature. Application of GV-based bias correction described by Henderson et al. (2017a) demonstrates a decrease in TMI-PR differences for both regional and tropics-averaged rain rate anomalies. The correction results in a decrease in TMI rainfall where stratiform rain is prevalent, but also increases convective rainfall leading to an overall closer agreement with GPCP. The bias correction increases $\mathrm{PR}$ rain rate estimates across all regimes and results in improved agreement with radiometer-based estimates when considering the response in precipitation to interannual variability in tropical SSTs. This precipitation response in version 7 TRMM TMI (PR) shifts from $20 \%$ (4\%) to $17 \%$ (10\%), which is closer to the GPCP value of $15 \%$.

The TMI and PR rain rate differences and climatologies will evolve over time with future iterations of the precipitation retrievals. The advantage of the selfsimilar regimes is the ability to diagnose climate-scale uncertainties in precipitation variability by providing a physical source to identify and subsequently correct for errors. The regime classification is largely based upon the vertical distribution of reflectivity and convective/ stratiform ratios in rainfall. While future changes in precipitation identification could impact the regime classification (e.g., Funk et al. 2013), the overall shifts observed in regional variability in regimes will likely not be affected. While not shown in this study, the spatial variability found in organized regimes (i.e., MCSs) as well their connection to the environment were observed to be similar to those observed when using MCSs defined by the TRMM Precipitation Feature Dataset (Liu et al. 2008). The consistency between the methodologies provides further confidence that the shifts in precipitation should be observed across other datasets as well. The regime-based analysis described here not only provides an improved understanding of interannual variability in TRMM rainfall but also provides a blueprint in precipitation variability in relation to its environment to aid in future model and satellite validation studies.

Acknowledgments. The authors wish to acknowledge Sue van den Heever (CSU) and Eric Maloney (CSU) for their comments and suggestions, Stephanie Henderson (CSU) and Brandon Wolding (CSU) for helping acquire and convert the ERA-Interim data along with their helpful comments, and Dr. Hiro Masunaga (Nagoya University) for providing composited AIRS data as a function of ENSO phase. This research was supported by NASA PMM Grants NNX16AE23G and NNX13AG30G.

\section{REFERENCES}

Alexander, M. A., N.-C. Lau, and J. D. Scott, 2004: Broadening the atmospheric bridge paradigm: ENSO teleconnections to the tropical west Pacific-Indian Oceans over the seasonal cycle and to the North Pacific in summer. Earth's Climate: The Ocean-Atmosphere Interaction, Geophys. Monogr., Vol. 147, Amer. Geophys. Union, 85-103, https://doi.org/10.1029/ $147 \mathrm{GM} 05$.

Awaka, J., T. Iguchi, and K. Okamoto, 1998: Early results on rain type classification by the Tropical Rainfall Measuring Mission (TRMM) Precipitation Radar. Proc. Eighth URSI Commission Open Symp., Aveiro, Portugal, Union Radio-Scientifique Internationale, 22-25.

Back, L. E., and C. S. Bretherton, 2006: Geographic variability in the export of moist static energy and vertical motion profiles in the tropical Pacific. Geophys. Res. Lett., 33, L17810, https:// doi.org/10.1029/2006GL026672.

— and - 2009: On the relationship between SST gradients, boundary layer winds and convergence over the tropical oceans. J. Climate, 22, 4182-4196, https://doi.org/10.1175/ 2009JCLI2392.1.

_ - Z. R. Hansen, and Z. Handlos, 2017: Estimating vertical motion profile top-heaviness: Reanalysis compared to satellite-based observations, stratiform rain fraction. J. Atmos. Sci., 74, 855-864, https://doi.org/10.1175/JAS-D-16-0062.1.

Barnes, H., and R. A. Houze Jr., 2013: The precipitating cloud population of the Madden-Julian Oscillation over the Indian and west Pacific Oceans. J. Geophys. Res., 118, 6996-7023, https://doi.org/10.1002/jgrd.50375.

Berg, W., C. Kummerow, and C. Morales, 2002: Differences between east and west Pacific rainfall systems. J. Climate, 15, 3659-3672, https://doi.org/10.1175/1520-0442(2002)015<3659: DBEAWP $>2.0$.CO;2.

, T. L'Ecuyer, and C. Kummerow, 2006: Rainfall climate regimes: The relationship of regional TRMM rainfall biases to the environment. J. Appl. Meteor. Climatol., 45, 434-454, https:// doi.org/10.1175/JAM2331.1. 
Carr, N., and Coauthors, 2015: The influence of surface and precipitation characteristics on TRMM TMI rainfall retrieval uncertainty. J. Hydrometeor., 16, 1596-1614, https://doi.org/ 10.1175/JHM-D-14-0194.1.

Chen, B., and C. Liu, 2016: Warm organized rain system over the tropical Pacific. J. Climate, 29, 3403-3422, https://doi.org/ 10.1175/JCLI-D-15-0177.1.

Chiodi, A. M., and D. E. Harrison, 2015: Global seasonal precipitation anomalies robustly associated with $\mathrm{El}$ Niño and $\mathrm{La}$ Niña events-An OLR perspective. J. Climate, 28, 6133-6159, https://doi.org/10.1175/JCLI-D-14-00387.1.

Dee, D. P., and Coauthors, 2011: The ERA-Interim reanalysis: Configuration and performance of the data assimilation system. Quart. J. Roy. Meteor. Soc., 137, 553-597, https://doi.org/ 10.1002/qj.828.

Elsaesser, G. S., and C. D. Kummerow, 2013: A multisensor observational depiction of the transition from light to heavy rainfall on subdaily time scales. J. Atmos. Sci., 70, 2309-2324, https://doi.org/10.1175/JAS-D-12-0210.1.

,-- T. T. S. L'Ecuyer, Y. N. Takayabu, and S. Shige, 2010: Observed self-similarity of precipitation regimes over the tropical oceans. J. Climate, 23, 2686-2698, https://doi.org/ 10.1175/2010JCLI3330.1.

Funk, A., C. Schumacher, and J. Awaka, 2013: Analysis of rain classifications over the tropics by version 7 of the TRMM PR 2A23 algorithm. J. Meteor. Soc. Japan, 91, 257-272, https:// doi.org/10.2151/jmsj.2013-302.

Gu, G., R. F. Adler, G. Huffman, and S. Curtis, 2007: Tropical rainfall variability on interannual-to-interdecadal and longer time scales derived from the GPCP monthly product. J. Climate, 20, 4033-4046, https://doi.org/10.1175/JCLI4227.1.

Handlos, Z. J., and L. E. Back, 2014: Estimating vertical motion profile shape within tropical weather states over the oceans. J. Climate, 27, 7667-7686, https://doi.org/10.1175/JCLI-D-13-00602.1.

Held, I. M., and B. J. Soden, 2006: Robust responses of the hydrological cycle to global warming. J. Climate, 19, 5686-5699, https://doi.org/10.1175/JCLI3990.1.

Henderson, D. S., C. D. Kummerow, D. A. Marks, and W. Berg, 2017a: A regime-based evaluation of TRMM oceanic precipitation biases. J. Atmos. Oceanic Technol., 34, 2613-2635, https://doi.org/ 10.1175/JTECH-D-16-0244.1.

$\longrightarrow,-$, and — $-2017 \mathrm{~b}$ : Sensitivity of rain-rate estimates related to convective organization: Observations from the Kwajalein, RMI, radar. J. Appl. Meteor. Climatol., 56, 1099-1119, https:// doi.org/10.1175/JAMC-D-16-0218.1.

Hitschfeld, W. and J. Bordan, 1954: Errors inherent in the radar measurement of rainfall at attenuating wavelengths. J. Meteor., 11, 58-67, https://doi.org/10.1175/1520-0469(1954) $011<0058$ :EIITRM $>2.0 . \mathrm{CO} ; 2$.

Hou, A. Y., and Coauthors, 2014: The Global Precipitation Measurement (GPM) Mission. Bull. Amer. Meteor. Soc., 95, 701722, https://doi.org/10.1175/BAMS-D-13-00164.1.

Houze, R. A., Jr., 1993: Cloud Dynamics. Academic Press, 573 pp.

_ 1997: Stratiform precipitation in regions of convection: A meteorological paradox? Bull. Amer. Meteor. Soc., 78, 21792196, https://doi.org/10.1175/1520-0477(1997)078<2179: SPIROC $>2.0 . \mathrm{CO} ; 2$.

2004: Mesoscale convective systems. Rev. Geophys., 42 RG4003, https://doi.org/10.1029/2004RG000150.

, D. C. Wilton, and B. F. Smull, 2007: Monsoon convection in the Himalayan region as seen by the TRMM Precipitation Radar. Quart. J. Roy. Meteor. Soc., 133, 1389-1411, https:// doi.org/10.1002/qj.106.
— K. L. Rasmussen, M. D. Zuluaga, and S. R. Brodzik, 2015: The variable nature of convection in the tropics and subtropics: A legacy of 16 years of the Tropical Rainfall Measuring Mission (TRMM) satellite. Rev. Geophys., 53, 994-1021, https://doi.org/ 10.1002/2015RG000488.

Iguchi, T., T. Kozu, R. Meneghini, J. Awaka, and K. Okamoto, 2000: Rain-profiling algorithm for the TRMM Precipitation Radar. J. Appl. Meteor., 39, 2038-2052, https://doi.org/ 10.1175/1520-0450(2001)040<2038:RPAFTT >2.0.CO;2.

_ - J. Kwiatkowski, R. Meneghini, J. Awaka, and K. Okamoto, 2009: Uncertainties in the rain profiling algorithm for the TRMM Precipitation Radar. J. Meteor. Soc. Japan, 87A, 1-30, https://doi.org/10.2151/jmsj.87A.1.

Kim, S. T., and J.-Y. Yu, 2012: The two types of ENSO in CMIP5 models. Geophys. Res. Lett., 39, L11704, https://doi.org/ 10.1029/2012GL052006.

Kirstetter, P.-E., Y. Hong, J. J. Gourley, Q. Cao, M. Schwaller, and W. Petersen, 2014: Research framework to bridge from the Global Precipitation Measurement Mission core satellite to the constellation sensors using ground-radar-based national mosaic QPE. Remote Sensing of the Terrestrial Water Cycle, Geophys. Monogr., Vol. 206, Amer. Geophys. Union, 61-79, https://doi.org/10.1002/9781118872086.

Kishore, P., and Coauthors, 2011: Global $\left(50^{\circ} \mathrm{S}-50^{\circ} \mathrm{N}\right)$ distribution of water vapor observed by COSMIC GPS RO: Comparison with GPS radiosonde, NCEP, ERA-Interim, and JRA-25 reanalysis data sets. J. Atmos. Sol.-Terr. Phys., 73, 1849-1860, https://doi.org/10.1016/j.jastp.2011.04.017.

Kummerow, C., W. Barnes, T. Kozu, J. Shiue, and J. Simpson, 1998: The Tropical Rainfall Measuring Mission (TRMM) sensor package. J. Atmos. Oceanic Technol., 15, 809-817, https:// doi.org/10.1175/1520-0426(1998)015<0809:TTRMMT>2.0.CO;2. , D. L. Randel, M. Kulie, N. Wang, R. Ferraro, S. J. Munchak, and V. Petkovic, 2015: The evolution of the Goddard profiling algorithm to a fully parametric scheme. J. Atmos. Oceanic Technol., 32, 2265-2280, https://doi.org/10.1175/JTECH-D-15-0039.1.

Lau, K., and H. T. Wu, 2011: Climatology and changes in tropical oceanic rainfall characteristics inferred from Tropical Rainfall Measuring Mission (TRMM) data (1998-2009). J. Geophys. Res., 116, D17111, https://doi.org/10.1029/ 2011JD015827.

Li, W., and C. Schumacher, 2010: Thick anvils as viewed by the TRMM Precipitation Radar. J. Climate, 24, 1719-1735, https:// doi.org/10.1175/2010JCLI3793.1.

Liu, C., and E. Zipser, 2013: Regional variation of morphology of the organized convection in the tropics and subtropics. J. Geophys. Res., 118, 453-466, doi:10.1029/2012JD018409.

$\longrightarrow$, and 2014: Differences between the surface precipitation estimates from the TRMM precipitation radar and passive microwave radiometer version 7 products. J. Hydrometeor., 15, 2157-2175, https://doi.org/10.1175/JHM-D-14-0051.1.

_, E. J. Zipser, D. J. Cecil, S. W. Nesbitt, and S. Sherwood, 2008: A cloud and precipitation feature database from 9 years of TRMM observations. J. Appl. Meteor. Climatol., 47, 27122728, https://doi.org/10.1175/2008JAMC1890.1.

_ , R. P. Allan, and G. J. Huffman, 2013: Co-variation of temperature and precipitation in CMIP5 models and satellite observations. Geophys. Res. Lett., 39, L13803, https://doi.org/ 10.1029/2012GL052093.

Marks, D. A., D. B. Wolff, D. S. Silberstein, A. Tokay, J. L. Pippitt, and J. Wang, 2009: Availability of high-quality TRMM ground validation data from Kwajalein, RMI: A practical application of the relative calibration adjustment technique. J. Atmos. 
Oceanic Technol., 26, 413-429, https://doi.org/10.1175/ 2008JTECHA1174.1.

Masunaga, H., 2013: A satellite study of tropical moist convection and environmental variability: A moisture and thermal budget analysis. J. Atmos. Sci., 70, 2443-2466, https://doi.org/10.1175/ JAS-D-12-0273.1.

— T. S. L'Ecuyer, and C. D. Kummerow, 2005: Variability in the characteristics of tropical precipitation systems. Part I: Spatial structure. J. Climate, 18, 823-840, https://doi.org/10.1175/ JCLI-3304.1.

Meneghini, R., T. Iguchi, T. Kozu, L. Liao, K. Okamoto, J. A. Jones, and J. Kwiatkowski, 2000: Use of the surface reference technique for path attenuation estimates from the TRMM Precipitation Radar. J. Appl. Meteor., 39, 2053-2070, https:// doi.org/10.1175/1520-0450(2001)040<2053:UOTSRT>2.0.CO;2.

Munchak, S. J., C. D. Kummerow, and G. Elsaesser, 2012: Relationships between the raindrop size distribution and properties of the environment and clouds inferred from TRMM. J. Climate, 25, 2963-2978, https://doi.org/10.1175/JCLI-D-11-00274.1.

Rasmusson, E. M., and T. H. Carpenter, 1982: Variations in tropical sea surface temperature and surface wind fields associated with the Southern Oscillation/El Niño. Mon. Wea. Rev., 110, 354-384, https://doi.org/10.1175/1520-0493(1982)110<0354: VITSST $>2.0 . C O ; 2$.

Ratnam, J. V., S. K. Behera, Y. Masumoto K. Takahashi, and T. Yamagata, 2012: Anomalous climatic conditions associated with the El Niño Modoki during boreal winter of 2009. Climate Dyn., 39, 227-238, https://doi.org/10.1007/s00382-011-1108-z.

Schumacher, C., and R. A. Houze Jr., 2000: Comparison of radar data from the TRMM satellite and Kwajalein oceanic validation site. J. Appl. Meteor., 39, 2151-2164, https://doi.org/ 10.1175/1520-0450(2001)040<2151:CORDFT >2.0.CO;2.

, and _ 2006: Stratiform precipitation production over subSaharan Africa and the tropical East Atlantic as observed by TRMM. Quart. J. Roy. Meteor. Soc., 132, 2235-2255, https:// doi.org/10.1256/qj.05.121.

_, _ and I. Kraucunas, 2004: The tropical dynamical response to latent heating estimates derived from the TRMM Precipitation Radar. J. Atmos. Sci., 61, 1341-1358, https:// doi.org/10.1175/1520-0469(2004)061<1341:TTDRTL>2.0.CO;2.

Seo, E.-K., S. Hristova-Veleva, G. Liu, M.-L. Ou, and G.-H. Ryu, 2015: Long-term comparison of collocated instantaneous rain retrievals from the TRMM Microwave Imager and Precipitation Radar over the ocean. J. Appl. Meteor. Climatol., 54, 867-879, https://doi.org/10.1175/JAMC-D-14-0235.1.

Shige, S., Y. N. Takayabu, W. Tao, and D. E. Johnson, 2004: Spectral retrieval of latent heating profiles from TRMM PR data. Part I: Development of a model-based algorithm. J. Appl. Meteor., 43, 1095-1113, https://doi.org/10.1175/1520-0450(2004)043<1095: SROLHP $>2.0$.CO;2.

- S. Kida, H. Ashiwake, T. Kubota, and K. Aonashi, 2013: Improvement of TMI rain retrievals in mountainous areas. J. Appl. Meteor. Climatol., 52, 242-254, https://doi.org/ 10.1175/JAMC-D-12-074.1.

Silberstein, D. S., D. B. Wolff, D. A. Marks, D. Atlas, and J. L. Pippitt, 2008: Ground clutter as a monitor of radar stability at Kwajalein, RMI. J. Atmos. Oceanic Technol., 25, 2037-2045, https://doi.org/10.1175/2008JTECHA1063.1.
Sobel, A. H., S. E. Yuter, C. S. Bretherton, and G. N. Kiladis, 2004: Large-scale meteorology and deep convection during TRMM KWAJEX. Mon. Wea. Rev., 132, 422-444, https://doi.org/ 10.1175/1520-0493(2004)132<0422:LMADCD>2.0.CO;2.

Soden, B. J., 2000: The sensitivity of the tropical hydrological cycle to ENSO. J. Climate, 13, 538-549, https://doi.org/10.1175/ 1520-0442(2000)013<0538:TSOTTH > 2.0.CO;2.

Steiner, M., R. A. Houze Jr., and S. E. Yuter, 1995: Climatological characterization of three-dimensional storm structure from operational radar and rain gauge data. J. Appl. Meteor., 34, 1978-2007, https://doi.org/10.1175/1520-0450(1995)034<1978: CCOTDS $>2.0 . \mathrm{CO} ; 2$.

Stephens, G. L., and Coauthors, 2010: Dreary state of precipitation in global models. J. Geophys. Res., 115, D24211, https:// doi.org/10.1029/2010JD014532.

Su, H., and J. H. Jiang, 2013: Tropical clouds and circulation changes during the 2006/07 and 2009/10 El Niños. J. Climate, 26, 399-413, https://doi.org/10.1175/JCLI-D-12-00152.1.

Tao, W., and Coauthors, 2001: Retrieved vertical profiles of latent heat release using TRMM rainfall products for February 1998. J. Appl. Meteor., 40, 957-982, https://doi.org/10.1175/ 1520-0450(2001)040<0957:RVPOLH >2.0.CO;2.

Tian, B., D. E. Waliser, E. J. Fetzer, and Y. L. Yung, 2010: Vertical moist thermodynamic structure of the Madden-Julian oscillation in atmospheric infrared sounder retrievals: An update and a comparison to ECMWF interim reanalysis. Mon. Wea. Rev., 138, 4576-4582, https://doi.org/10.1175/2010MWR3486.1.

Vecchi, G. A., and B. J. Soden, 2007: Global warming and the weakening of the tropical circulation. J. Climate, 20, 43164340, https://doi.org/10.1175/JCLI4258.1.

_ Where do we stand? Wiley Interdiscip. Rev.: Climate Change, 1, 260-270, https://doi.org/10.1002/wcc.33.

Wang, J.-J., R. F. Adler, and G. Gu, 2008: Tropical rainfall-surface temperature relations using Tropical Rainfall Measuring Mission precipitation data. J. Geophys. Res., 113, D18115, https://doi.org/10.1029/2007JD009540.

Watanabe, M., J.-S. Kug, F.-F. Jin, M. Collins, M. Ohba, and A. T. Wittenberg, 2012: Uncertainty in the ENSO amplitude change from the past to the future. Geophys. Res. Lett., 39, L20703, https://doi.org/10.1029/2012GL053305.

Wolff, D. B., D. A. Marks, E. Amitai, D. S. Silberstein, B. L. Fisher, A. Tokay, J. Wang, and J. L. Pippitt, 2005: Ground validation for the Tropical Rainfall Measuring Mission (TRMM). J. Atmos. Oceanic Technol., 22, 365-380, https://doi.org/ 10.1175/JTECH1700.1.

Yokoyama, C., E. J. Zipser, and C. Liu, 2014: TRMM-observed shallow versus deep convection in the eastern Pacific related to large-scale circulations in reanalysis datasets. J. Climate, $\mathbf{2 7}$, 5575-5592, https://doi.org/10.1175/JCLI-D-13-00315.1.

Yuter, S. E., and R. A. Houze Jr., 1998: The natural variability of precipitating clouds over the western Pacific warm pool. Quart. J. Roy. Meteor. Soc., 124, 53-99, https://doi.org/10.1002/ qj. 49712454504.

Zipser, E., D. Cecil, C. Liu, S. W. Nesbitt, and S. Yorty, 2006: Where are the most intense thunderstorms on Earth? Bull. Amer. Meteor. Soc., 87, 1057-1071, https://doi.org/10.1175/ BAMS-87-8-1057. 